OECDpublishing

\title{
A NEW APPROACH TO SKILLS MISMATCH
}

AMANDINE BRUN-SCHAMMÉ MARTIN REY

OECD PRODUCTIVITY WORKING PAPERS

July 2021 No. 24 


\section{OECD PRODUCTIVITY WORKING PAPERS}

The OECD Productivity Working Papers are associated with the Global Forum on Productivity that provides a forum for mutual exchange of information and fosters international co-operation between public bodies with responsibility for promoting productivity-enhancing policies, including in undertaking joint policy analysis. It offers a platform for exchanging views, experiences and information, institutional and governance arrangements and government structures, with a view towards developing better policies. The Forum extends existing work in the OECD through a well-prioritised and coherent stream of analytical work serving the policy research needs of participants on the drivers of productivity growth.

This paper has been authorised for publication by Luiz de Mello, Director, Policy Studies Branch, Economics Department, Álvaro Santos Pereira, Director, Country Studies Branch, Economics Department, and Andrew Wyckoff, Director, Directorate for Science, Technology and Innovation.

OECD Productivity Working Papers should not be reported as representing the official views of the OECD or of its member countries. The opinions expressed and arguments employed are those of the author(s).

Comments on OECD Productivity Working Papers are welcome and may be sent to: productivity@oecd.org OECD Productivity Working Papers are published on: oe.cd/productivity

Series: OECD Productivity Working Paper Series

ISSN 2413-9424

Please cite this paper as:

Brun-Schammé, A. and Rey, M., "A new approach to skills mismatch", OECD Productivity Working Papers, 2021-24, OECD

Publishing, Paris.

This document and any map included herein are without prejudice to the status of or sovereignty over any territory, to the delimitation of international frontiers and boundaries and to the name of any territory, city or area.

The statistical data for Israel are supplied by and under the responsibility of the relevant Israeli authorities. The use of such data by the OECD is without prejudice to the status of the Golan Heights, East Jerusalem and Israeli settlements in the West Bank under the terms of international law.

(C) OECD (2021)

You can copy, download or print OECD content for your own use, and you can include excerpts from OECD publications, databases and multimedia products in your own documents, presentations, blogs, websites and teaching materials, provided that suitable acknowledgment of OECD as source and copyright owner is given. All requests for commercial use and translation rights should be submitted to PubRights@oecd.org. 


\section{ABSTRACT/RÉSUMÉ}

\section{A new approach to skills mismatch}

Skills mismatch - the sub-optimal use of an individual's skills in their occupation - can be a source of dissatisfaction for workers and a brake for productivity growth. In our view, a difference in the level of skills within an occupation is not sufficient to infer that a skills mismatch exists. Since skills-mismatch is the result of a disparity between the supply and demand of labour, the quantifying of skills-mismatch must therefore be based on the mechanisms involved in this disparity. We propose to include in our measurement the level of education and field of study, which are key markers of an individual's skill level in the labour market. This makes it possible to identify, among individuals whose skill level differs from others within an occupation, those whose training profile can (or cannot) explain this situation. Through using the OECD PIAAC 2012 survey, this paper first identifies with data for France, individuals who present an apparent skills mismatch according to the framework proposed. Following an international comparison of "apparent skills mismatch rates", we conclude this study by observing how the different groups identified differ in terms of how they perceive their employment situation as well as their individual characteristics.

JEL classification: O40; 120; J20; J24.

Keywords: skills, skills mismatch, training, occupation, level of education, labour market.

\section{Une nouvelle approche de l'inadéquation des compétences}

L'inadéquation des compétences - l'utilisation sous-optimale des compétences d'un individu dans son métier - peut être une source d'insatisfaction pour les travailleurs et un frein à la croissance de la productivité. À notre sens, un écart de niveau de compétences au sein d'un métier n'est pas suffisant pour appréhender une situation d'inadéquation de compétences. Étant donné que cet écart provient d'un mauvais appariement entre l'offre et la demande de travail, une mesure de l'inadéquation doit s'appuyer sur les mécanismes intervenant dans cet appariement et non sur une simple mesure du niveau de compétences. Nous proposons d'intégrer dans la mesure de l'inadéquation des compétences, le niveau de diplôme et le domaine de formation des individus, signaux essentiels du niveau de compétences d'un individu sur le marché du travail. Ceci permet d'appréhender, parmi les individus dont le niveau de compétences se distingue des autres au sein d'un métier, ceux dont le profil de formation peut expliquer ce positionnement. En mobilisant l'enquête PIAAC 2012 de I'OCDE, cet article identifie avec données françaises, les individus qui présentent une inadéquation apparente des compétences selon le cadre proposé. À la suite d'une comparaison internationale des " taux d'inadéquation apparente des compétences ", nous concluons cette étude en observant comment les différents groupes identifiés diffèrent en matière de perception de leur situation d'emploi ainsi que de leurs caractéristiques individuelles.

Classification JEL : O40; I20; J20; J24.

Mots-clés : compétences, inadéquation des compétences, formation, profession, niveau d'éducation, marché du travail. 


\section{Table of contents}

A new approach to skills mismatch $\quad 5$

1. Introduction 5

2. The link between skill level and training profile 6

2.1. The general skill score increases with the level of education, and there are bigger gaps in numeracy than in literacy

2.2. Disparities in average skill scores by field of study

2.3. Unsurprisingly, the average skill level observed for an occupation increases with the proportion of people with qualifications

3.1. Description of the method and the different types of mismatch 11

3.2. Training profiles

4. Characterisation of individuals with mismatched skills 13

4.1. At the national level 13

4.2. International comparisons 18

5. Further consideration $\quad 19$

5.1. From skills mismatch to under/over-skilling $\quad 19$

5.2. Cognitive and task-based skills 25

6. Conclusion 26

$\begin{array}{ll}\text { References } & 27\end{array}$

$\begin{array}{ll}\text { Annex A. The OECD's PIAAC survey } & 28\end{array}$

\section{Tables}

Table 1. Inter-decile ratios for basic skill scores in France according to the level of education 8

Table 2. Determinants of the PIAAC skill score

Table 3. Median general skill scores and standard deviations by training profile 12

Table 4. Share of participants who completed the PIAAC basic skills assessment digitally by training profile 12

Table 5. Apparent skills mismatch in occupation and training profile 13

Figure 1. PIAAC score by level of education attained $\quad 7$

Figure 2. Skills and level of education attained by occupation 10

Figure 3. Type of apparent skills mismatch and level of education 14

Figure 4. Proportion of individuals with skill scores below or above the proxies for occupation and training
profile, by level of education

Figure 5. Apparent skills mismatch by ISCO category 16

Figure 6. Proportion of individuals with skill scores above or below the proxies for their occupation and training

profile by ISCO category 17

Figure 7. Apparent skills mismatch by country 18

Figure 8. Proportion of individuals with scores above and below the proxies for occupation and training profile 18

Figure 9. Median general basic skill scores by occupation in different European countries 19

Figure 10. Occupation categories according to median general skill score 20 
Figure 11. Structure of the classification of skills mismatches by occupation category and positioning in relation to the proxies for the occupation and training profile

Figure 12. Characteristics of individuals in Group 1, Group A occupations and at national level

Figure 13. Characteristics of individuals in Group 4, Group A occupations and at national level

Figure 14. Characteristics of individuals in Group 3, Group C occupations and at national level

Figure 15. Characteristics of individuals in Group 6, Group C occupations and at national level 


\title{
A new approach to skills mismatch
}

\author{
By Amandine Brun-Schammé and Martin Rey ${ }^{1}$
}

\section{Introduction}

1. In its 2019 report, the French National Productivity Board (NPB, 2019) posited skills mismatch as a potential explanatory factor for the slowdown in productivity in France. The term "skills mismatch" refers to the sub-optimal use of an individual's skills in the activity he or she performs, i.e. an under-use of skills or, conversely, a situation where the skill level is below that required.

2. Several methods have been developed in the economic literature to try to measure the degree of skills mismatch in different countries.

3. Some approaches, which can be described as "subjective", are based on data from surveys that ask employees how they feel about their job (Allen and van der Velden, 2001; Green and Mcintosh, 2007; Hauret and Marguerit, 2020). Skills mismatch refers to a situation where an employee feels that his or her skill level does not match the level required for the job, either because it is too high or because he or she feels that it is too low in relation to the needs of the job. For example, in $2015,45 \%$ of workers in France, Luxembourg and Germany considered their skills to be mismatched to their jobs according to the responses to the European Working Condition Survey (EWCS) ${ }^{2}$. Workers in all countries surveyed reported being more often over-skilled than under-skilled (Hauret and Marguerit, 2020). However, these methods may be subject to measurement bias because they are based on individuals' perceptions of their own skills, as well as those expected in the occupation concerned. Individuals may therefore tend to overestimate their skills ("overconfidence effect"), or conversely, they may undervalue themselves and attribute their success to external factors such as luck, relationships or chance, rather than to their own skills ("imposter syndrome").

4. Other approaches make it possible to infer the existence of a skills mismatch by defining the level of skills required using a quantitative method. These consist of establishing a proxy for the level of skills required for each occupation, and then considering the individuals furthest away from this proxy as having mismatched skills (Quintini, 2014, McGowan and Andrews, 2015, Pellizzari and Fichen, 2017). The process of measuring a skills mismatch consists of two steps. First, the OECD's PIAAC Adult Skills Survey asks workers whether they feel that they "have the skills needed to cope with tasks that are more demanding than those they have to perform in their current job" and whether they "need further training

\footnotetext{
${ }^{1}$ Corresponding authors are: Amandine Brun-Schammé (amandine.brun-schamme@strategie.gouv.fr) and Martin Rey (martin.rey@pm.gouv.fr) of France Stratégie, the French Prime Minister's Strategic Planning Unit, at the time of initial publication. The authors would like to thank the Directorate for Research, Studies and Statistics of the French Ministry of Labour (Dares), the members of the French National Productivity Board (NPB) and the OECD for their advices and data provision.

${ }^{2}$ Which of the following statements would best describe your skills in your own work? a. I need further training to cope well with my duties; $b$. My present skills correspond well with my duties; $c$. I have the skills to cope with more demanding duties.
} 
to cope well with their duties". In the second step, the direct evaluation, through a series of exercises and simulations, of basic skills in literacy, numeracy and problem-solving in technology-rich environments included within the PIAAC survey are used to develop a "skills score" for each participant. The skill scores of workers who give negative answers to these two questions are used to create a quantitative scale of the skills needed to perform tasks for each occupation (single-digit ISCO). In a second step, using this scale of skill scores, minimum and maximum threshold values are determined so as to define what it means to be a "well-matched worker". Respondents who score below (or above) this minimum (or maximum) threshold in their occupation are considered to have mismatched skills.

5. Based on the PIAAC survey data, it appears that the vast majority of workers considered to be skill mismatched when a subjective approach is used are ultimately not deemed to have mismatched skills when the second approach is adopted (Pellizzari and Fichen, 2017). In France, 20\% of employees are said to be skill mismatched, with $11 \%$ being "over-skilled" while $9 \%$ are "under-skilled". In comparison, $25 \%$ of German employees and about $33 \%$ of Italian and Spanish employees are reported to be skill mismatched (McGowan and Andrews, 2015).

6. One of the limitations of this approach is that differences in skill levels between individuals working in the same occupation are not necessarily indicative of a skills mismatch, but may relate to differences in individual performance. A simple measure of variance cannot therefore isolate only those individuals who are in a job that is inappropriate to their skill level. In our view, the indicator needs to be able to identify cases where the signals enabling a match between the skills held (supply) and skills required (demand) have not worked properly.

7. To do this, we propose a method of measuring skills mismatch that takes into account the heterogeneity of occupations, as well as individuals' education and training, i.e. the highest level of education attained and their field of study. This makes it possible to identify which individuals with an apparent skill mismatch - i.e. those with a substantially different skill level vis-à-vis others within their occupation - have a training profile that can explain the difference in skill level. This approach makes it possible to infer whether an apparent skill mismatch relates to an individual being in a job that is inappropriate to their skill level or to the individual's performance. In both cases, continuing education has an important role to play in correcting the apparent skills mismatch, especially for individuals with the lowest skill levels.

\section{The link between skill level and training profile}

8. This study is based on data from the OECD's 2012 PIAAC survey, which is a unique source providing an international comparison of adult skills on a harmonised basis ${ }^{3}$. The next survey is planned for 2022.

9. The PIAAC survey is an international survey which is composed of two elements. The first is a series of questions asked to each participant pertaining to the current and previous employment history, their personal characteristics, their educational background and how they perceive their current employment both in terms of satisfaction and working conditions as well as the task content of their occupations. In the second part of the survey, each respondent participated in a series of exercises and simulations which were designed to evaluate their basic skills in numeracy, literacy and for some, their problem-solving in technology-rich environments. Through this evaluation, each participant is allocated a score going from 0 to 500 , for each basic skill type, for which a higher score indicates a greater degree of control in this domain.

\footnotetext{
${ }^{3}$ See annex. A
} 
10. Whilst all participating countries included the evaluation program for basic skills in literacy and numeracy, problem-solving in technology-rich environments was not systematically evaluated (particularly of note being France). Even though this information would have been a considerable asset to our study due to the ever-increasing role of technologies in the work place, this type of skill has been omitted from the analysis.

\subsection{The general skill score increases with the level of education, and there are bigger gaps in numeracy than in literacy}

11. The average general skill score observed ${ }^{4}$ increases with the level of education. The average skill score according to the PIAAC survey in France, as in other countries, is higher for individuals with a postbaccalaureate level of education (290 for those with vocational qualifications and 303 for those with nonvocational higher education qualifications) than that observed for individuals whose highest-level qualification is the baccalaureate or pre-baccalaureate brevet (254). The general skills score achieved by individuals with no qualifications is 213. At a given level of education, these differences are more pronounced for numeracy than for literacy (see Figure 1).

12. Differences in skill scores between individuals are also smaller for the most highly educated. The higher the level of education, the lower the inter-decile and inter-quartile ratios. There is therefore less heterogeneity in the overall level of skills observed among the most highly educated.

Figure 1. PIAAC score by level of education attained
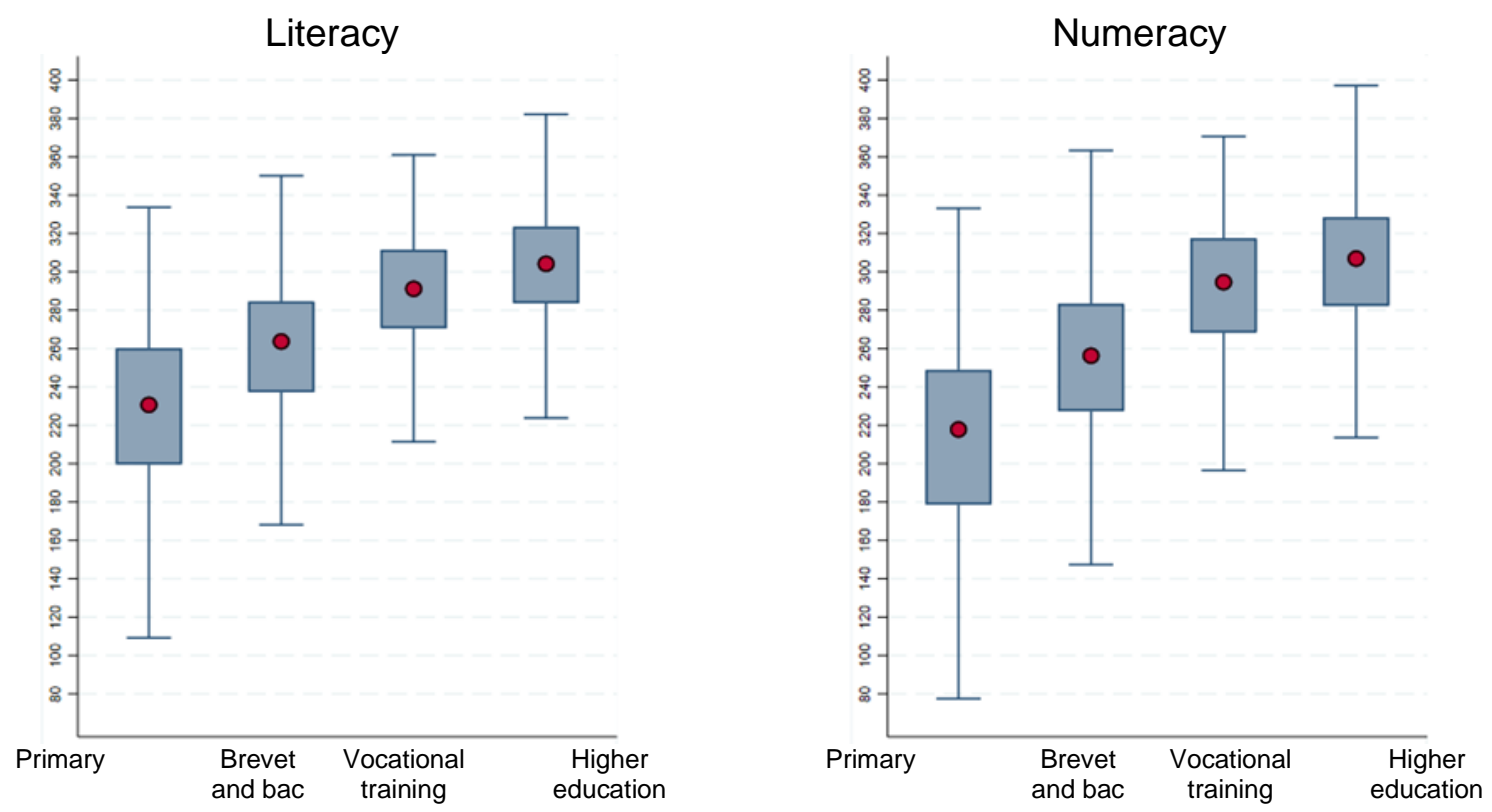

Note: The extremes correspond to the 1st and 9th deciles. The rectangles represent the 1st and 3rd quartiles, the red dot is at the median. Source: PIAAC 2012, OECD, Calculations by France Stratégie.

13. The differences are particularly marked for individuals without post-baccalaureate qualifications, as shown by the inter-decile ratios in the following table.

\footnotetext{
4 The average skills score is calculated as the average of the literacy and numeracy scores obtained by individuals based on their responses to the PIAAC survey questionnaire.
} 
Table 1. Inter-decile ratios for basic skill scores in France according to the level of education

\begin{tabular}{ccc}
\hline INDEX (D9-D1)/D9 & Post-baccalaureate qualification & Pre-baccalaureate qualification \\
\hline General index & $35 \%$ & $61 \%$ \\
\hline Literacy & $36 \%$ & $59 \%$ \\
\hline Numeracy & $40 \%$ & $73 \%$ \\
\hline
\end{tabular}

Source: PIAAC 2012, OECD, Calculations by France Stratégie.

\subsection{Disparities in average skill scores by field of study}

14. Disparities in average general skill scores are also observed from the PIAAC survey for different fields of study. The average skill score for individuals who have received training in "science and technology" is 281 , compared with 254 for those with training in services (sales, administration, etc.).

Table 2. Determinants of the PIAAC skill score

\begin{tabular}{c|c|c|c|c|c|c|c}
\hline Dependent variables & \multicolumn{1}{c|}{ Overall PIAAC score } & \multicolumn{2}{c}{ PIAAC numeracy score } & \multicolumn{2}{c}{ PIAAC literacy score } \\
\hline \multicolumn{7}{c}{ Individual control } \\
\hline Individual control & Yes & Yes & Yes & Yes & Yes & Yes \\
\hline \multicolumn{7}{c}{ Education } \\
\hline
\end{tabular}

Reference: primary, lower secondary or upper secondary education of basic education

\begin{tabular}{|c|c|c|c|c|c|c|}
\hline Brevet and baccalaureate & $32.8^{* * *}$ & $31.6^{\star * *}$ & $36.9^{* * *}$ & $35.2^{* * *}$ & $28.8^{* * *}$ & $28.1^{* * *}$ \\
\hline & $(1.52)$ & (2.11) & $(1.79)$ & $(2.46)$ & $(1.54)$ & $(2.13)$ \\
\hline $\begin{array}{l}\text { Vocational training and other higher } \\
\text { vocational education }\end{array}$ & $65.1^{* * *}$ & $63.1^{* * *}$ & $73.6^{\star * *}$ & $71.1^{* * *}$ & $56.7^{* * *}$ & $55.0^{\star \star \star}$ \\
\hline & $(2.06)$ & (2.63) & $(2.47)$ & (3.11) & $(2.09)$ & (2.73) \\
\hline Higher education & $78.6^{\star \star *}$ & $75.9^{\star \star \star}$ & $88.0^{* * *}$ & $84.8^{* \star *}$ & $69.2^{* \star \star}$ & $67.0^{\star * \star}$ \\
\hline & $(1.75)$ & $(2.56)$ & $(2.12)$ & (2.94) & $(1.76)$ & (2.62) \\
\hline \multicolumn{7}{|c|}{ Field of study } \\
\hline \multicolumn{7}{|c|}{ Reference: lack of specialisation } \\
\hline \multirow[t]{2}{*}{ Social sciences } & & 0.32 & & -0.26 & & 0.92 \\
\hline & & (1.98) & & $(2.26)$ & & $(2.16)$ \\
\hline \multirow[t]{2}{*}{ Science and technology } & & $9.31^{* * *}$ & & $12.25^{* * *}$ & & $6.38^{* * *}$ \\
\hline & & (2.16) & & (2.45) & & (2.36) \\
\hline Health and social care & & -2.65 & & -4.46 & & -0.84 \\
\hline
\end{tabular}




\begin{tabular}{c|c|c|c|c|c|c}
\hline & & $(2.86)$ & & $(3.33)$ & & $(2.91)$ \\
\hline Services & & $-7.47^{* * *}$ & & $-8.56^{* * *}$ & & $-6.38^{* * *}$ \\
\hline & & $(2.15)$ & & $(2.53)$ & & $(2.20)$ \\
\hline
\end{tabular}

\begin{tabular}{c|c|c|c|c|c|c}
\hline Constant & $214.0^{* \star *}$ & $218.0^{* * *}$ & $193.0^{* \star *}$ & $198.5^{* \star *}$ & $235.0^{* \star *}$ & $237.6^{* * *}$ \\
\hline & $(7.63)$ & $(7.71)$ & $(8.62)$ & $(8.69)$ & $(7.94)$ & $(8.07)$ \\
\hline Comments & & & & & & \\
\hline R-2 & 4.33 & 4.33 & 4.33 & 4.33 & 4.33 & 4.33 \\
\hline
\end{tabular}

Standard deviations in brackets ${ }^{* * *} p<0.01,{ }^{* *} p<0.05,{ }^{*} p<0.1$

Note: for each regression the following individual controls were used: Age, Age^2, Gender, Region.

Source: PIAAC 2012, OECD, Calculations by France Stratégie.

15. In order to establish the determinants of the skill score, a linear regression of the average skill score is carried out firstly for the level of education, and secondly, for both the level of education and field of study, controlling for individual characteristics (age, gender, region) in each regression used. Each participant may only record one field of study for their highest level of degree obtained. For individuals who have not obtained degrees further then the Brevet or Baccalaureate, a considerable share of participants recorded having received training in "General Training" or did not respond to the relevant questions. These individuals compose the field of study reference in our regression analysis noted as "No Specialisation" in the table above. Here, "No Specialisation" refers to the fact that these specific individuals have not completed a level of education that offers a specialisation or focus on a particular subject, the education received is one of the earliest forms of education which provide early general formations geared towards youth.

16. All other things being equal, and controlling for individual characteristics as well as field of study, an individual with a university-level qualification scores 76 points higher in the assessment of general basic skills (numeracy and literacy) than an individual with only the primary, lower secondary or upper secondary level of basic education.

17. The linear regression confirms what can be seen from the descriptive data, namely that the skill score increases with the level of education. Furthermore, it appears that at an equivalent level of education, individuals with science and technology background have the highest skill scores, while those with a specialisation in services have the lowest skill scores.

\subsection{Unsurprisingly, the average skill level observed for an occupation increases with the proportion of people with qualifications}

18. Looking at the average skill scores observed by occupation (ISCO) 5 , it is not surprising that the higher the proportion of people with qualifications working in an occupation, the higher the average skill score. For reasons of statistical reliability, only those occupations for which we have sufficient observations from the PIAAC survey are included in this study which collectively represent $89 \%$ of the 6 employed population.

\footnotetext{
${ }^{5}$ Here we use the two-digit ISCOs.

6 These occupations are: cleaners and helpers; skilled building and related occupations, excluding electricians; machine and plant operators; health professionals; labourers in mining, construction and public works, manufacturing and transport; food processing, woodworking, garment and other craft and related trades; drivers and mobile plant
} 
19. As a corollary, the average general skill scores observed are the lowest among the ISCO categories with the highest proportion of workers with education below or equivalent to the second stage of basic education. Among these occupations, there is also a lower average score for numeracy than for literacy.

20. The occupations with the highest proportions of people with qualifications, are naturally those with the highest average skill scores observed. For example, among managers and executives in management, production and specialised services, almost $83 \%$ have a post-baccalaureate qualification, and their average skill score is 304. In comparison, among individuals working in skilled construction and related occupations, excluding electricians, only $4 \%$ have a post-baccalaureate qualification, and their general skill score is around 231 (see Figure 2).

Figure 2. Skills and level of education attained by occupation

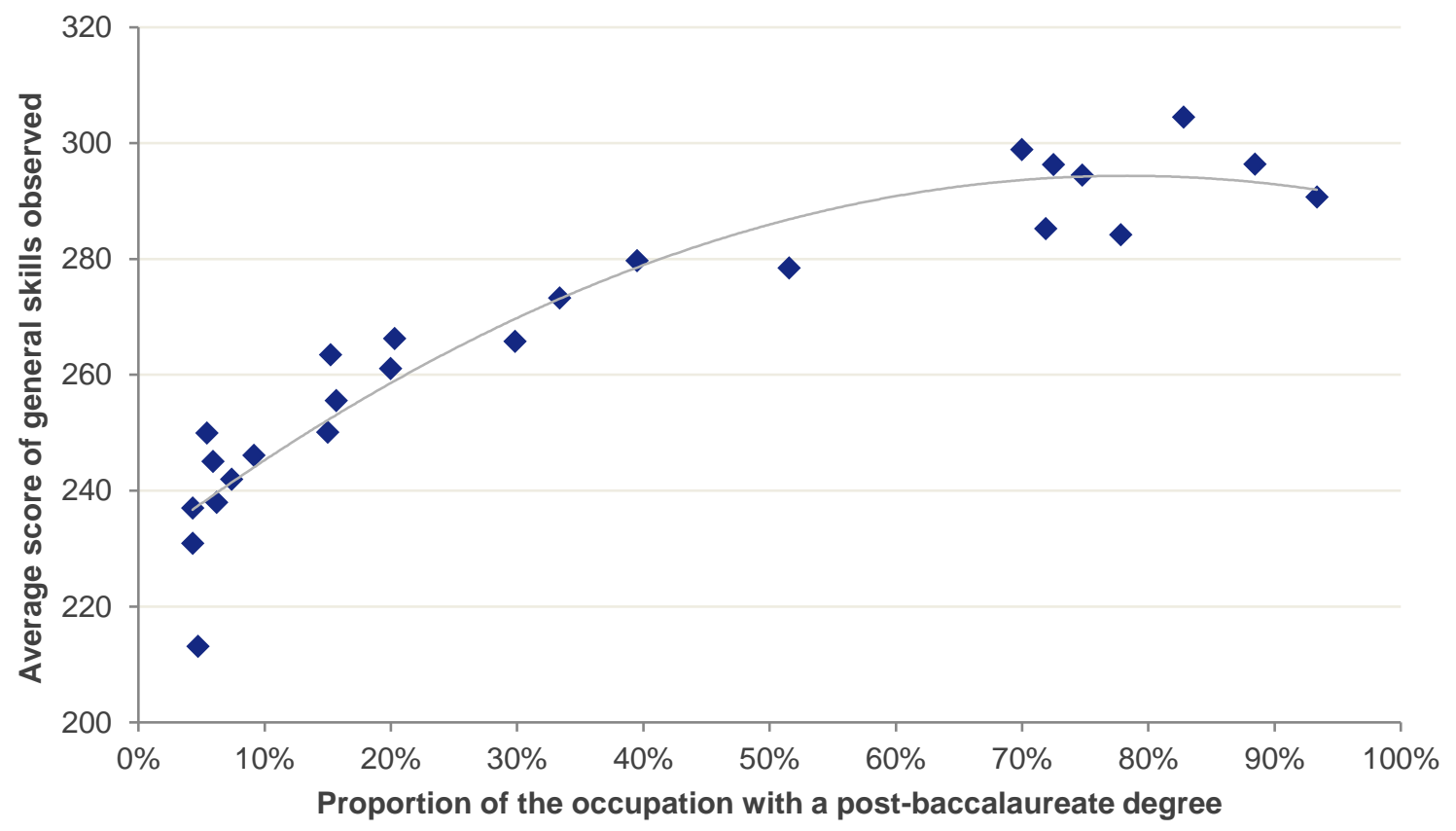

Note: in most occupations, the differences between literacy and numeracy skill scores are relatively small. Source: PIAAC 2012, OECD, Calculations by France Stratégie.

\section{Determining a skills mismatch}

21. We have opted for the term 'apparent skills mismatch' to refer to the situation of individuals whose skill level is substantially different from others. We will cover the issue of under/over-skilling in a second step, when analysing the apparent skills mismatch. In our view, differences in skill levels do not necessarily mean that individuals are in jobs that are inappropriate to their skills level.

operators; personal services workers; skilled metal, mechanical construction and related occupations; market-oriented skilled agricultural workers; shopkeepers and salespersons; protective services workers; office clerks; science and technology associate professionals; accounting and purchasing; accounting, finance and administration associate professionals; legal, social and related associate professionals; health associate professionals; health professionals; legal, social and cultural professionals; business administration professionals; information and communications technology professionals; administrative and commercial managers; teaching professionals; senior officials and chief executives, production and specialised services managers. 


\subsection{Description of the method and the different types of mismatch}

22. Following the example of the quantitative methods developed in the economic literature, we established a proxy for the "expected" level of skills by occupation. While Quintini (2014) and McGowan and Andrews (2015) use the responses from the PIAAC survey, which asks workers whether they believe they "have the skills to cope with more demanding duties than those required by their current job" and whether they consider they "need further training to cope well with their duties" to construct a quantitative scale of skills required to perform tasks for each occupation (single-digit ISCO), we favour a method based on the skill scores observed for each occupation in the PIAAC survey. This allows us to avoid possible biases that may exist when individuals are asked about their skills and the level required in their occupation. We established a proxy for the expected skill level using the median and one standard deviation of the skill scores observed in the PIAAC survey for each occupation (two-digit ISCO). An 'apparent skill mismatch' exists when an individual's skill level is outside one standard deviation from the median score for his/her occupation. $29 \%$ of the people employed in the selected ISCO categories show an apparent skills mismatch within their occupation in France.

23. The training profile, i.e. the highest level of education attained by an individual and his/her field of study, is generally a good indicator of skills level. As shown by the linear regression carried out in the first part of this study, there is a link between an individual's skills level and his/her training profile. However, in some cases the skills level may not match the training profile. The use of the training profile as a signal of skills level in the recruitment process may then prove unreliable, and result in individuals being in inappropriate jobs given their skill level. In other cases, the individual's skill level is in line with his/her training profile, but the signal representing this may be misunderstood by employers, and once again lead to an apparent mismatch of skills within the occupation. Taking only the standard deviation relating to the proxy for the occupations does not allow us to capture the mechanism by which the mismatch occurs; we therefore decided to incorporate the training profile into our study. Using international comparisons, we can infer potential differences in the structures and levels of skills between France and other countries.

24. In the same way as for the occupations, we established a proxy for the skill level by training profile (combining the highest level of education attained and the field of study) using the median and one standard deviation of the skill scores observed in the PIAAC survey. Individuals whose skill score is outside the standard deviation of the median skill score for their training profile are considered to have a skills mismatch with their training profile.

25. From this, we can identify four different scenarios:

- a skills mismatch within the occupation, combined with a training profile mismatch. In this case, the individual has a skill level that is more than one standard deviation above (or below) the median skill score for his/her occupation and training profile. The training profile is, in this case, not a good indicator of the skills held by the individual and the labour market has not been able to appreciate this. We therefore have a dysfunction on the supply and demand side of the labour market.

- a skills mismatch within the occupation. The individual has a skill level above (or below) the standard deviation from the median skill score for his/her occupation. He/she is within the standard deviation of the median skill score for his/her training profile. Here, the training profile is a good indicator of skills, but despite this, the labour market has not properly appreciated this information.

- a skills mismatch with the training profile. The individual has a skills level above (or below) the standard deviation of the median skill score for his/her training profile. He/she is within the standard deviation of the median skill score for his/her occupation. Here, the training profile is not a good indicator, but the labour market may have perceived this and drawn on other information when making the match.

- no apparent skills mismatch in terms of profile and occupation. The individual's skill level is within the standard deviation of the median skill score for his/her occupation and training profile. 


\subsection{Training profiles}

26. The training profiles are a combination of the highest level of education attained and the different fields of study. We selected four categories for education - primary, brevet-baccalaureate, higher vocational education (BTS, DUT) and higher education (university studies, grandes écoles) - and five fields of training ${ }^{7}$. This makes twenty combinations, but only thirteen have a sufficient number of observations to be deemed observable. As mentioned above, for each combination of training profile, the median score for general skills was established. Individuals whose skill score is outside the standard deviation of the median score are considered to have a skills mismatch according to their training profile. Table 3 summarises the median general skill scores and standard deviations.

Table 3. Median general skill scores and standard deviations by training profile

\begin{tabular}{l|c|c|c|c|c}
\hline & $\begin{array}{c}\text { No } \\
\text { specialisation }\end{array}$ & $\begin{array}{c}\text { Social sciences and } \\
\text { humanities, arts }\end{array}$ & $\begin{array}{c}\text { Science } \\
\text { and technology }\end{array}$ & $\begin{array}{c}\text { Health and } \\
\text { social care }\end{array}$ & Services \\
\hline Primary & $225+-50$ & - & - & - & - \\
\hline Brevet and baccalaureate & $259+-39$ & $267+-38$ & $267+-40$ & $255+-35$ & $250+-38$ \\
\hline Higher vocational education & - & $286+-35$ & $300+-32$ & $290+-38$ & $287+-33$ \\
\hline Higher education & - & $299+-35$ & $318+-34$ & $294+-35$ & - \\
\hline
\end{tabular}

Note: each box indicates the median score observed in basic general skills and the standard deviation. For individuals with a higher vocational education qualification and training in services, a median score of 287 was observed, with a standard deviation of 33 . Some combinations were not used for reasons of statistical reliability (insufficient number of observations) or non-observation of the combination.

Source: PIAAC 2012, OECD, Calculations by France Stratégie.

Table 4. Share of participants who completed the PIAAC basic skills assessment digitally by training profile

\begin{tabular}{l|c|c|c|c|c}
\hline & $\begin{array}{c}\text { No } \\
\text { specialisation }\end{array}$ & $\begin{array}{c}\text { Social sciences and } \\
\text { humanities, arts }\end{array}$ & $\begin{array}{c}\text { Science } \\
\text { and technology }\end{array}$ & $\begin{array}{c}\text { Health and } \\
\text { social care }\end{array}$ & Services \\
\hline Primary & $53 \%$ & - & - & - & - \\
\hline Brevet and baccalaureate & $78 \%$ & $87 \%$ & $80 \%$ & $81 \%$ & $77 \%$ \\
\hline Higher vocational education & - & $95 \%$ & $94 \%$ & $88 \%$ & $85 \%$ \\
\hline Higher education & - & $92 \%$ & $96 \%$ & $85 \%$ & - \\
\hline
\end{tabular}

Note: each box indicates the share of participants who completed the PIAAC basic skills assessment digitally by training profile. For individuals with a higher vocational education qualification and training in services, $85 \%$ of these participants completed the PIAAC skills assessment digitally.

Source: PIAAC 2012, OECD, Calculations by France Stratégie.

\footnotetext{
7 Social sciences and humanities (law, economics, sociology, history, geography, languages, art and pedagogical sciences), science and technology (courses in science, computer science, mathematics, natural sciences, engineering, construction), health and social care, services (sales, administration) and no specialisation.
} 
27. When interpreting the previously listed results, it is important to consider how the overall framework and structure of the PIAAC survey may influence them. Each participant of the PIAAC survey is subjected to a series of basic skills evaluation. Prior to this however, the participant is asked whether his computer skills are sufficient enough to conduct these evaluations through a digital platform, if the participant replies negatively, the evaluation was conducted in a paper-based fashion. Whilst a high share of the overall cohort proceeded with the evaluation digitally, this was not systematic and those with higher levels of education were indeed more likely to do so (see table. 4). Whilst these differences are negligible for those with education above the Brevet and Baccalaureate, previous studies have shown that differences in the methods in which skills evaluations are conducted may influence the overall outcome. For example, Zinn, Landrock and Gnambs (2020) identified systematically larger test results for participants in the German National Education Panel Survey for those whose "Scientific Literacy" was tested in paper-based studies compared to the alternative computer-based assessment. This effect was particularly pronounced for those in the lower half of the skills level spectrum.

\section{Characterisation of individuals with mismatched skills}

\subsection{At the national level}

28. Of the $29 \%$ of individuals with an apparent skills mismatch in their occupation, $61 \%$ (or $17.6 \%$ of those employed in the occupations observed) also have an apparent skills mismatch in their training profile. For these individuals, the traditional mechanisms for matching labour supply and demand have not worked well, and the labour market has not been able to identify their skill levels. $11.4 \%$ of those employed in the occupations observed have an apparent skills mismatch with their occupation proxy, but not with their training profile. For these individuals, this apparent skills mismatch may mean they are in a job inappropriate to their skill level. If this is the case, it would be preferable for them to work in an occupation more in line with their skill level; however, the mismatch may also reflect a wide range of training profiles within the occupation, without there being a mismatch in individuals' skills.

29. In addition, $9.4 \%$ of those employed in the occupations observed have a skills mismatch in their training profile but no skills mismatch in their occupation, and $61.6 \%$ of those employed in the occupations observed have no skills mismatch in either their occupation or their training profile.

Table 5. Apparent skills mismatch in occupation and training profile

\begin{tabular}{l|c|c}
\hline & $\begin{array}{c}\text { Mismatch } \\
\text { in relation to training profile }\end{array}$ & $\begin{array}{c}\text { No mismatch in skills } \\
\text { in relation to } \\
\text { training profile }\end{array}$ \\
\hline Mismatch in relation to occupation & $17.6 \%$ & $11.4 \%$ \\
\hline No mismatch in relation to occupation & $9.4 \%$ & $61.6 \%$ \\
\hline
\end{tabular}

Note: $17.6 \%$ of individuals have a skill level above (or below) the standard deviation of the median skill score for their occupation and training profile.

Source: PIAAC 2012, OECD, Calculations by France Stratégie.

30. Among the individuals with skill mismatches in relation to their occupation alone, the least qualified are over-represented (34\% have reached a primary level of education, see figure. 3 ). It is necessary to distinguish individuals according to the position of their skill level in relation to the proxies to observe differences according to the level of education. 
Figure 3. Type of apparent skills mismatch and level of education

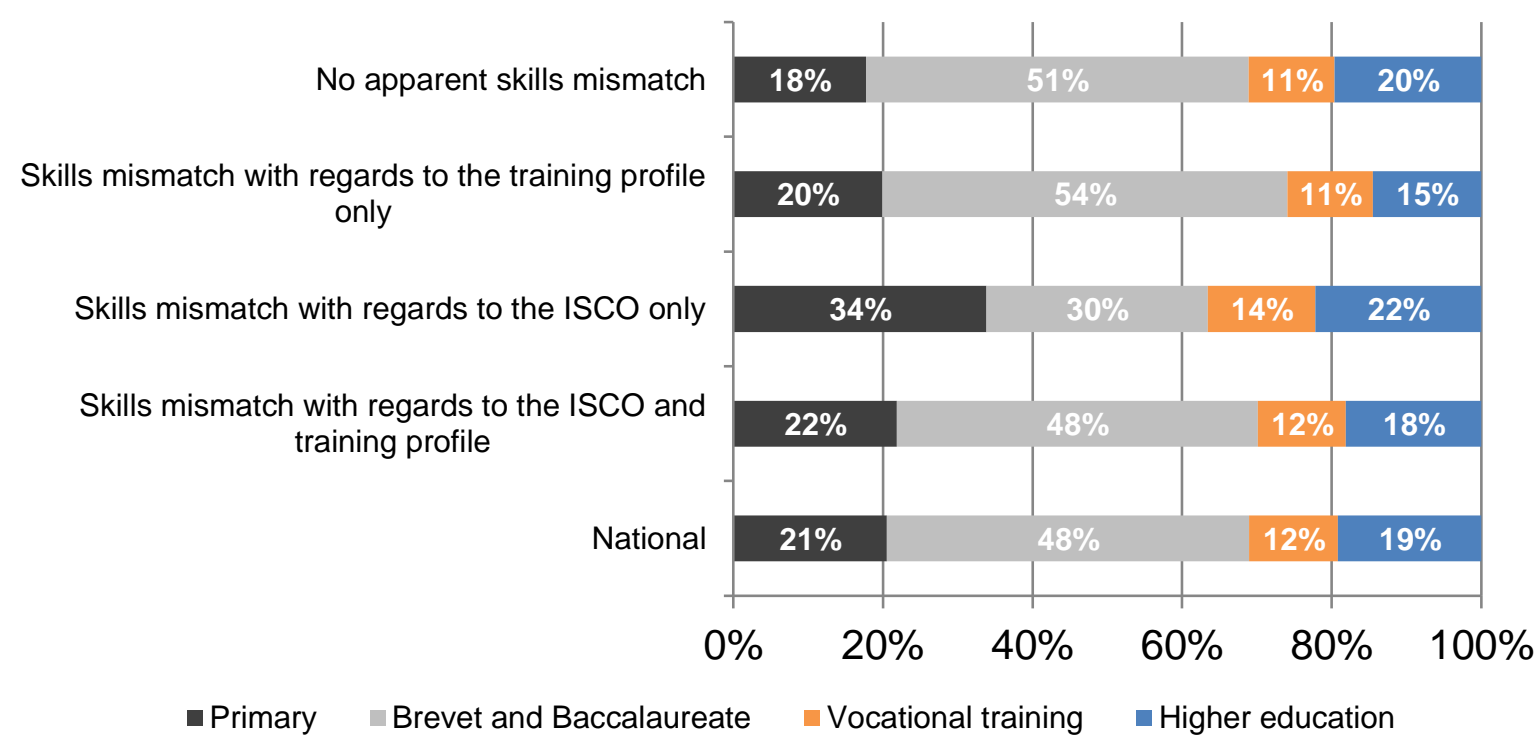

Note: this chart shows the distribution of the highest qualification held according to the type of mismatch observed. Among individuals with a skill level that represents a mismatch in relation to the proxy for their occupation only, $34 \%$ have not gone beyond primary, lower secondary or upper secondary basic education. At the national level, among those employed in the occupations observed, $21 \%$ have this level of education. Thus, individuals with a primary level of education are over-represented among those with an apparent mismatch with respect to their occupation and profile, at a rate of $13 \%$.

Source: PIAAC 2012, OECD, Calculations by France Stratégie.

31. We then focus our analysis on the apparent skills mismatch by occupation, combined (or not) with an apparent skills mismatch by training profile.

32. Those with few qualifications are over-represented among individuals whose skill score is below the proxy for their occupation. Holders of a post-baccalaureate qualification are overrepresented among individuals whose skill score is higher than the proxy for their occupation.

33. Among individuals with an apparent skills mismatch due to a skill level below the proxy for their occupation, $96 \%$ hold a baccalaureate at best (see figure. 4). For those with an apparent skills mismatch in terms of occupation and training profile by a score below the proxy, $78 \%$ hold the baccalaureate at most. Holders of a baccalaureate or lower account for $69 \%$ of the total population observed. Conversely, the most highly educated are over-represented among individuals with an apparent skills mismatch with scores above the proxy. Thus, $72 \%$ of the individuals among the occupations observed with a skill score higher than the proxy for their occupation have a post-baccalaureate qualification ( $28 \%$ have a higher vocational education qualification and $44 \%$ have a higher education qualification). Moreover, $43 \%$ (18\% and $25 \%$ respectively) had a skill score above the proxy for both their occupation and training profile. Holders of post-baccalaureate qualifications represent $31 \%$ of the total population observed (12\% have a higher vocational education qualification and $19 \%$ hold a higher education qualification). 
Figure 4. Proportion of individuals with skill scores below or above the proxies for occupation and training profile, by level of education

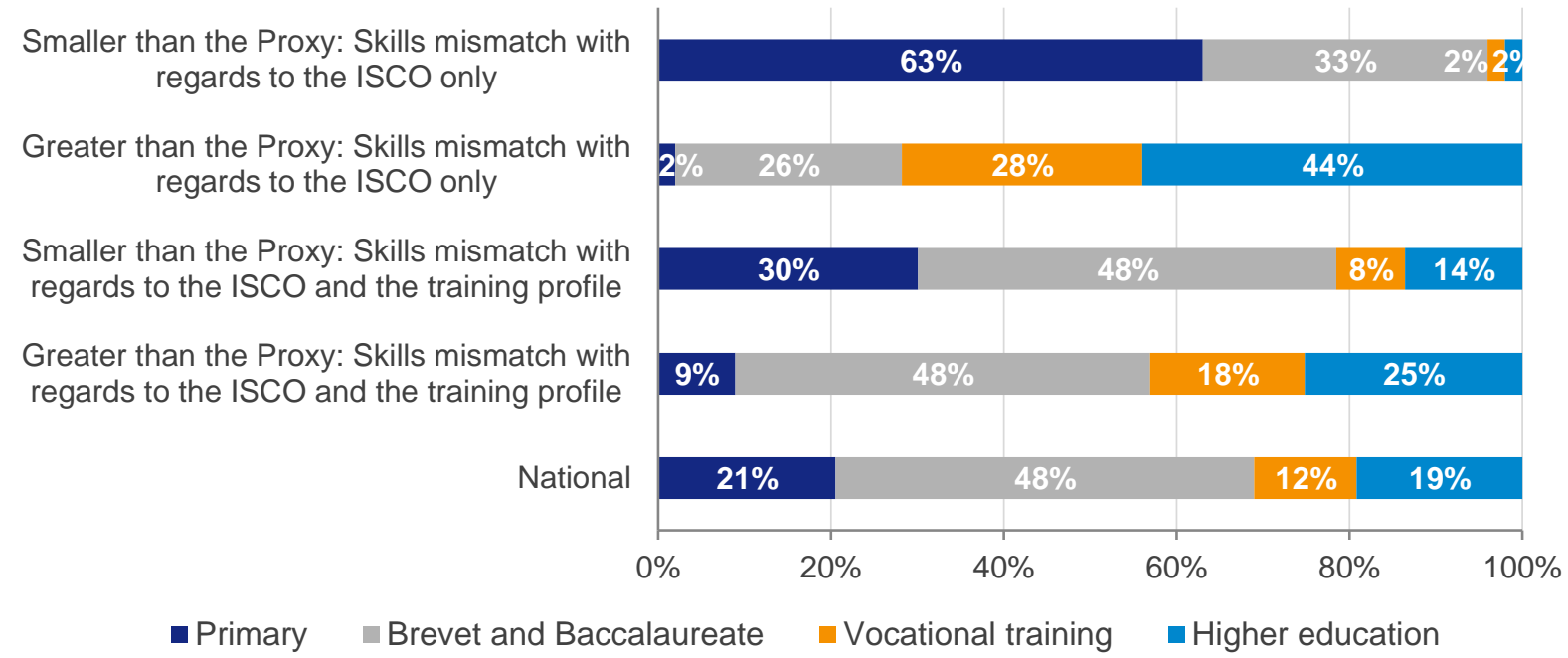

Note: the distribution of qualifications held according to the type of mismatch observed is shown in this chart, with a breakdown according to the individual's position in terms of the apparent skills mismatch. Among individuals whose skill level is higher than the proxies for their occupation and training profile, only $9 \%$ have not gone beyond the primary, lower secondary or upper secondary level of basic education. At the national level, among those employed in the occupations observed, $21 \%$ have this level of education. Thus, individuals with a primary level of education are under-represented among those with a skill level above the proxies for their occupation and training profile (-12\%).

Source: PIAAC 2012, OECD, Calculations by France Stratégie.

\section{An apparent skills mismatch is significant in some occupations, whether skilled or unskilled.}

35. Of the occupations for which we have sufficient data for analysis, some have a significant proportion of individuals with an apparent skills mismatch. This applies to both skilled and unskilled occupations.

36. There are more individuals with an apparent skills mismatch both in their occupation and their training profile. For "science and engineering associate professionals", 19\% of individuals have an apparent skills mismatch in terms of their occupation and training profile and $16 \%$ in terms of their occupation alone (see figure. 5). For "personal care workers", the proportions are $20 \%$ and $13 \%$ respectively. 
Figure 5. Apparent skills mismatch by ISCO category

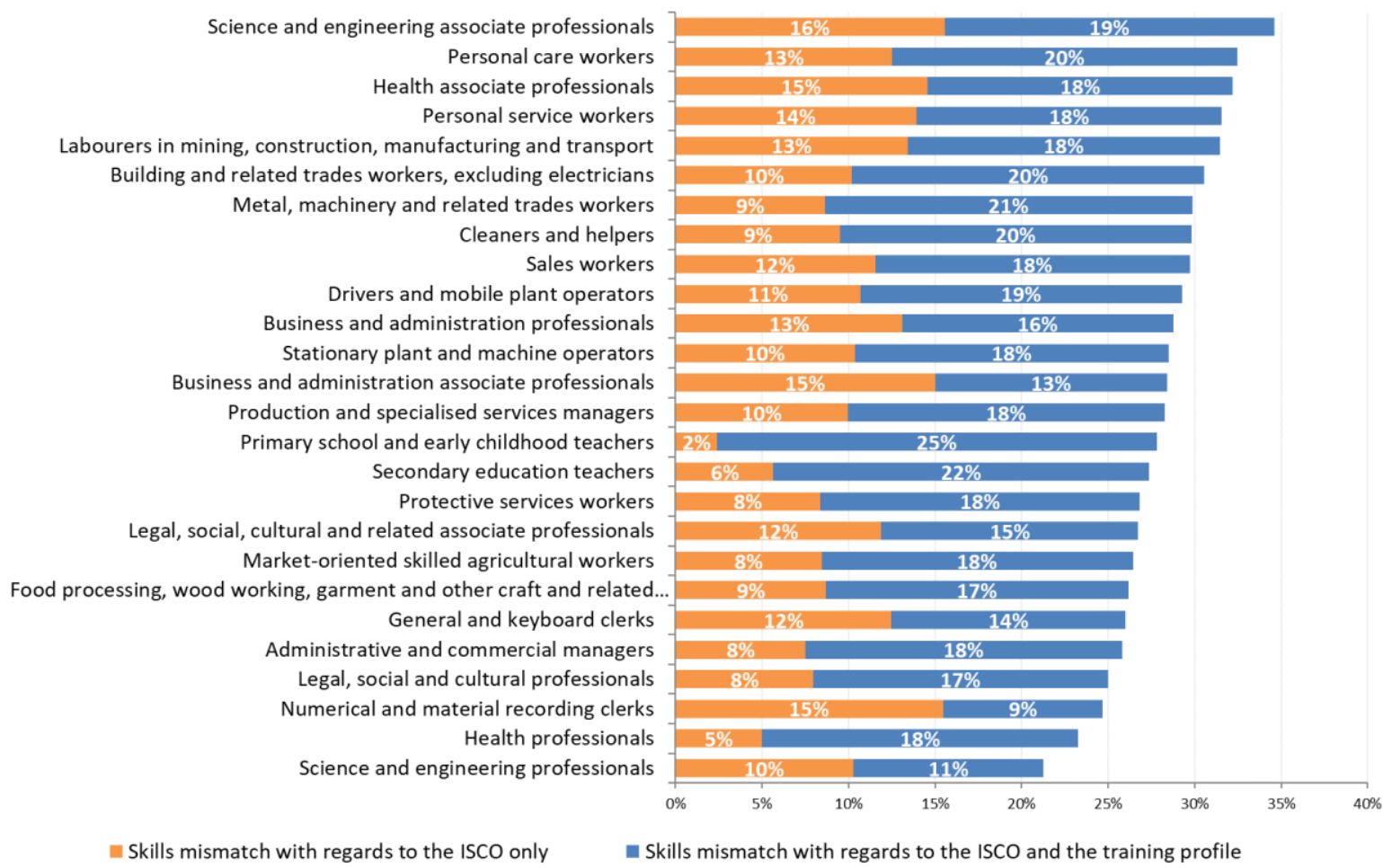

Scope: Occupations with at least 62 observations in the 2012 PIAAC survey.

Note: the proportion of the workforce with an apparent skills mismatch in occupation only and those with an apparent skills mismatch in both the occupation and training profile are shown by occupation.

Source: PIAAC 2012, OECD, Calculations by France Stratégie.

37. In some occupations, mismatches are primarily accounted for by individuals whose skill levels are below the proxies for their occupation and training profiles. This is the case, for example, for "building and related trade workers, excluding electricians" (14\%, see figure. 6), "metal, machinery and related trade workers" (13\%) and "cleaners and helpers" (17\%). These occupations have a large proportion of people with no qualifications and lower general basic skills scores. Moreover, a key feature of building occupations and cleaners and helpers is that a large proportion of the workers have an immigrant background (Mini, 2012). Although the educational level of the immigrant population is improving, it remains heterogeneous and lower than that of the non-immigrant population (France Stratégie, 2019). This could explain why a significant proportion of workers in these occupations have a lower literacy and numeracy skill score than the proxy for their occupation and training profile. 
Figure 6. Proportion of individuals with skill scores above or below the proxies for their occupation and training profile by ISCO category

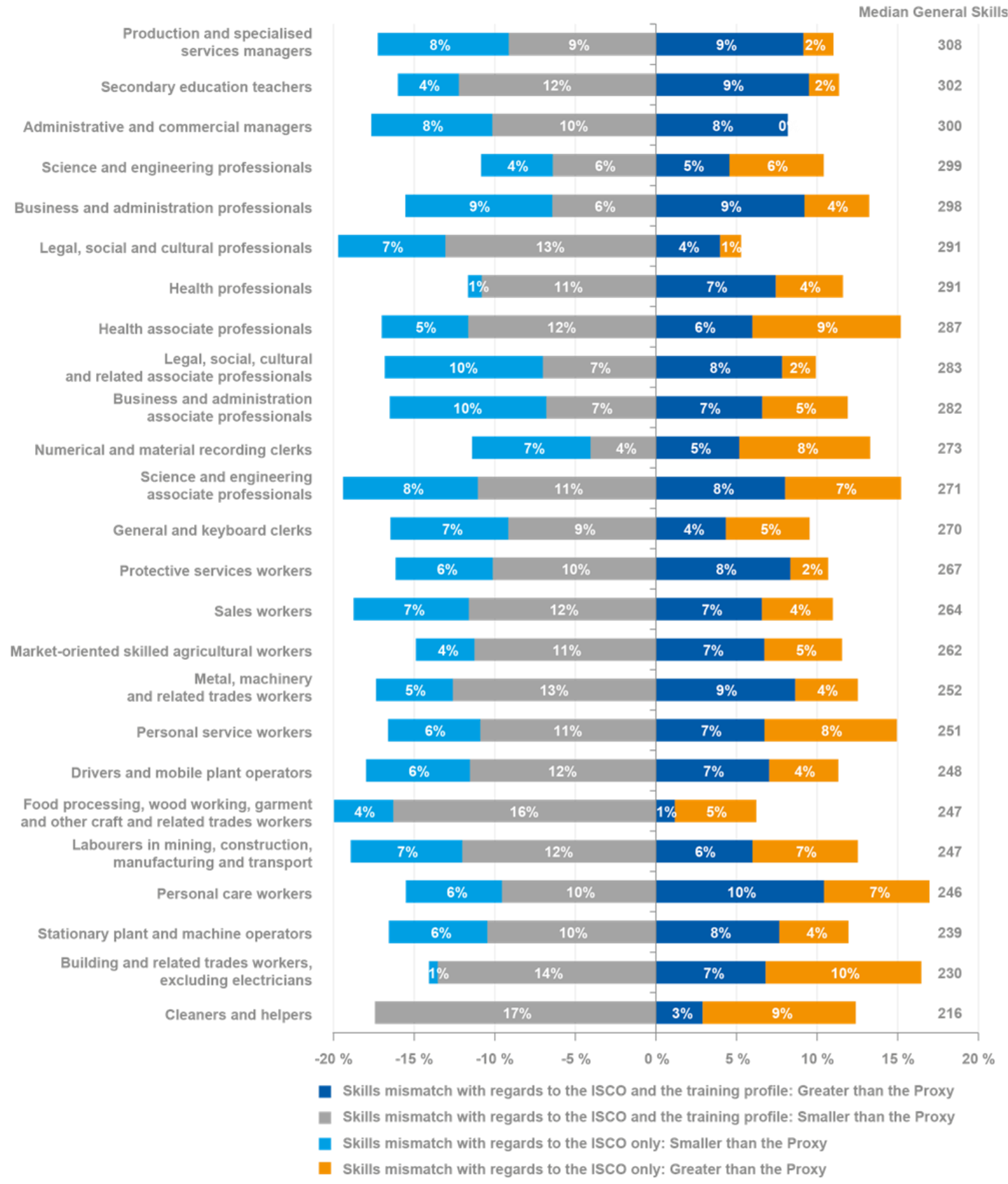

Note: the proportion of the workforce with an apparent skills mismatch in relation to their occupation only and those with apparent skills mismatches in relation to both their occupation and training profile is shown by occupation, with a breakdown according to their position in relation to the proxies for the occupation and occupation/training profile.

Source: PIAAC 2012, OECD, Calculations by France Stratégie. 


\subsection{International comparisons}

\section{Skills mismatch is not particular to France but also concerns its European neighbours in similar proportions.}

39. Between $9 \%$ and $11 \%$ of individuals show an apparent skills mismatch with their occupation and between $17 \%$ and $19 \%$ of individuals show an apparent skills mismatch with both their occupation and training profile (see figure. 7). To make an international comparison, we selected occupations for which there were sufficient observations in all the countries studied. This may mean slight discrepancies for France compared to the results presented above. With our new selection, only $57 \%$ of the population in employment in France was observed, with similar rates for the other countries.

Figure 7. Apparent skills mismatch by country

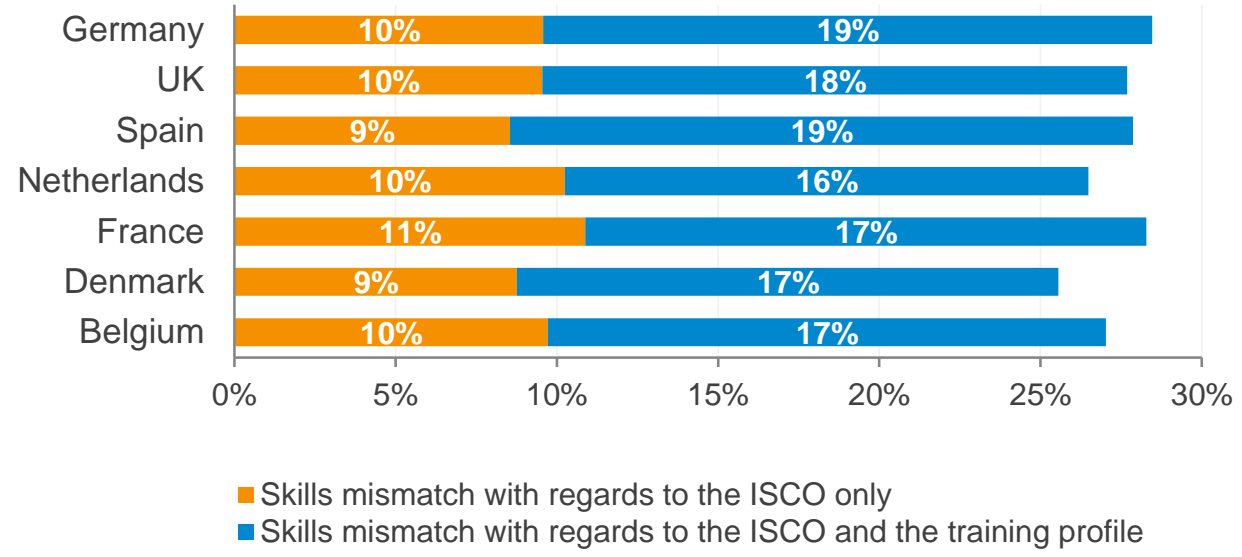

Note: in all countries, the proportion of individuals with skill scores below the proxies for both the occupation and training profile is higher in all countries than the proportion of individuals with a higher score.

Source: PIAAC 2012, OECD, Calculations by France Stratégie.

Figure 8. Proportion of individuals with scores above and below the proxies for occupation and training profile

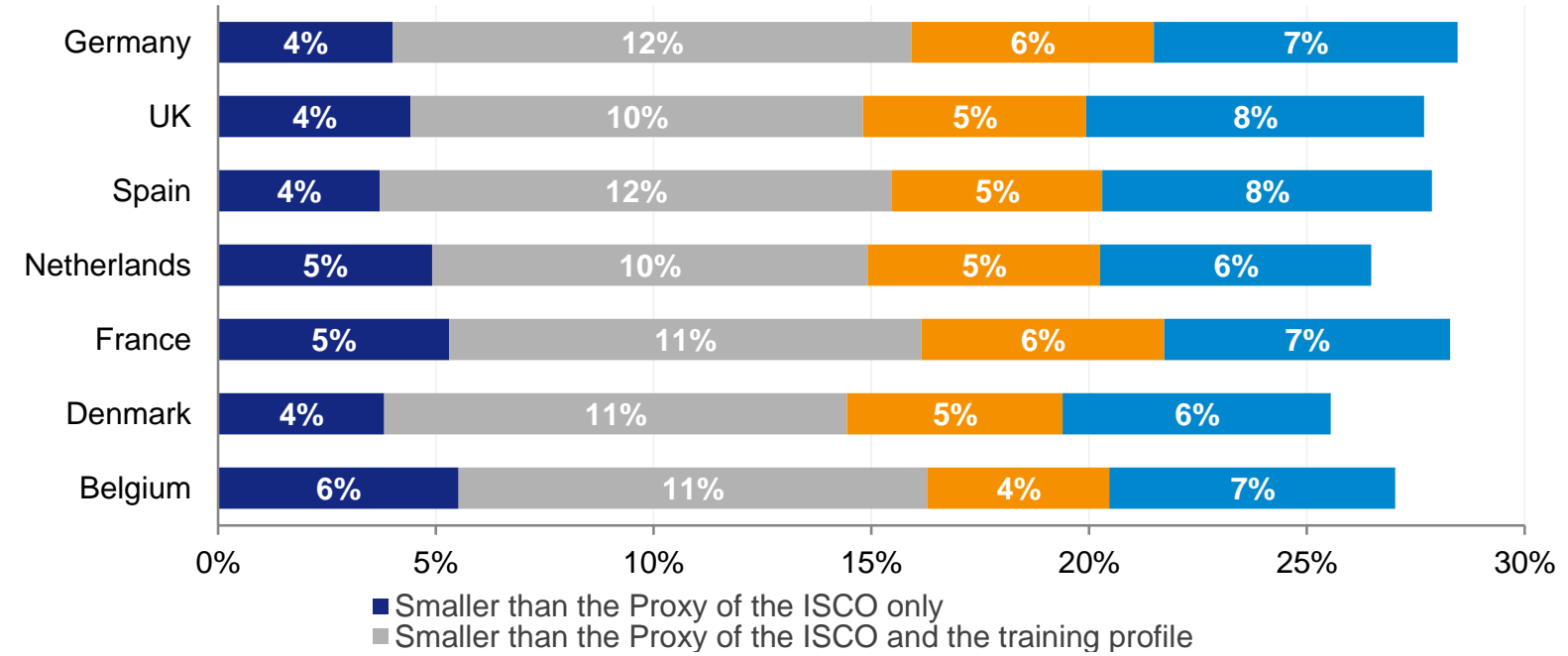

Note: in both Germany and France, individuals with apparent skill mismatches whose skill level is higher than the proxy for their occupation represent $6 \%$ of the workforce in employment observed in these countries.

Source: PIAAC 2012, OECD, Calculations by France Stratégie. 
40. These results indicate that France does not differ from other European countries in terms of the structure of the apparent skills mismatch. Nevertheless, there is a difference in adult skill levels for the occupations studied: the level of skills of people in employment is relatively low for France compared to other European countries, as shown in the following chart.

\section{Figure 9. Median general basic skill scores by occupation in different European countries}

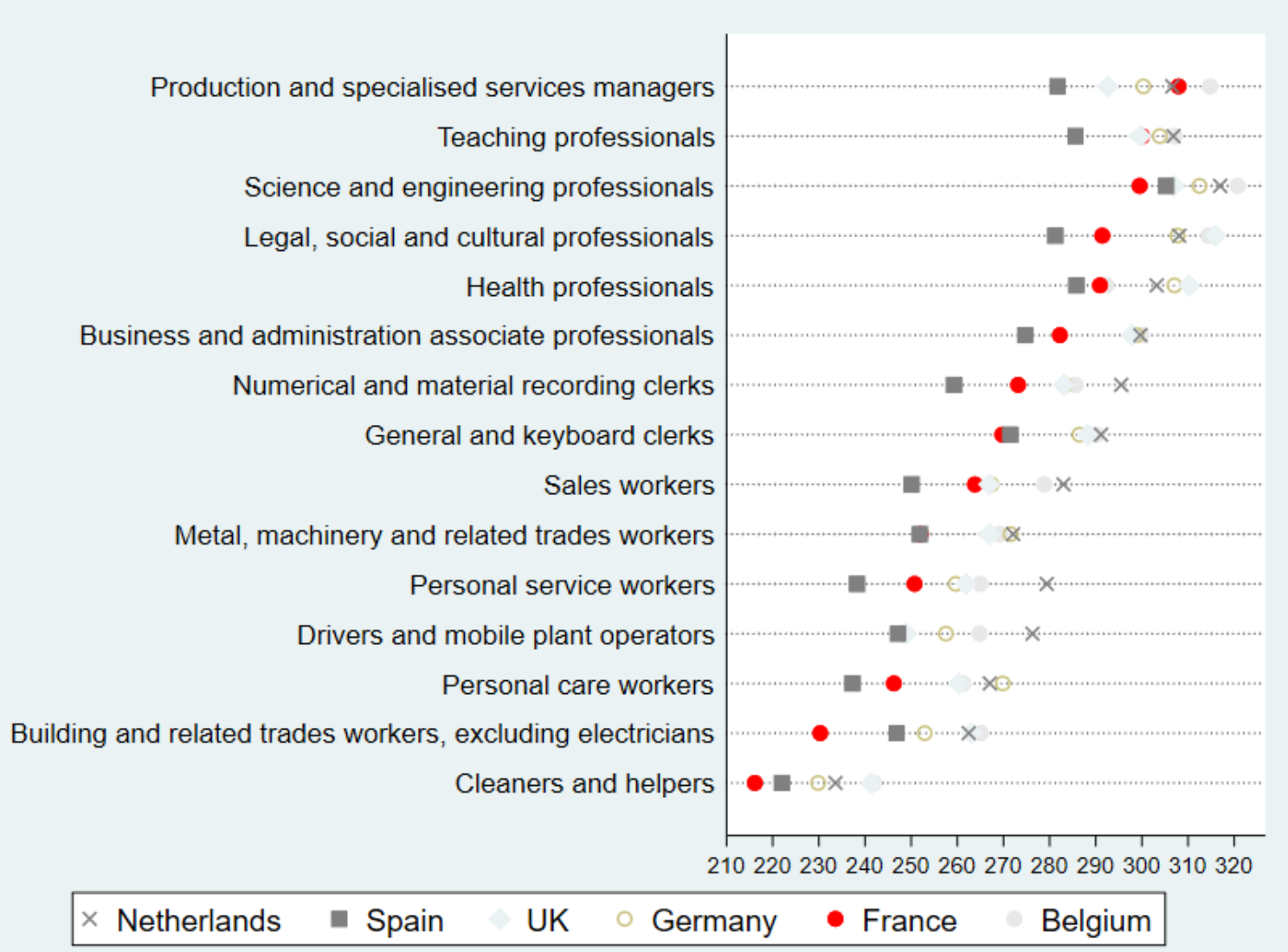

Source: PIAAC 2012, OECD, Calculations by France Stratégie.

\section{Further consideration}

\subsection{From skills mismatch to under/over-skilling}

41. The significant difference in the general skill level of individuals in relation to the standard deviation of the median skill score for their occupation and/or their training profile shows an apparent skills mismatch, which in our view does not necessarily represent under/over-skilling, i.e. a situation where individuals are in jobs that are inappropriate to their skill level. Let us take the example of "cleaners and helpers" whose median general skill score is among the lowest for all ISCO categories. $17 \%$ of individuals in this category have a PIAAC survey skill score that is below the standard deviation of the median score for their occupation and training profile. It would appear that rather than being in a job inappropriate to their skill level, these individuals require training.

42. We have established a classification in order to refine our analysis of the skills mismatches observed. This allows us to better understand what is due to individuals being in jobs inappropriate to their 
skill level and what may stem from their work performance. It is important to note that the distinction between skill level and performance is not necessarily clear-cut, depending on the case, but it enables us to identify the skills mismatch in the labour market more effectively.

43. We first distinguish between three categories of occupation according to their median level of general skills. The first category includes the occupations with the lowest median skill scores, according to the PIAAC survey (fourth quartile). The second category contains the occupations with median skill scores in the middle of the range (second and third quartiles), and the third category represents occupations with the highest skill scores (first quartile).

\section{Figure 10. Occupation categories according to median general skill score}

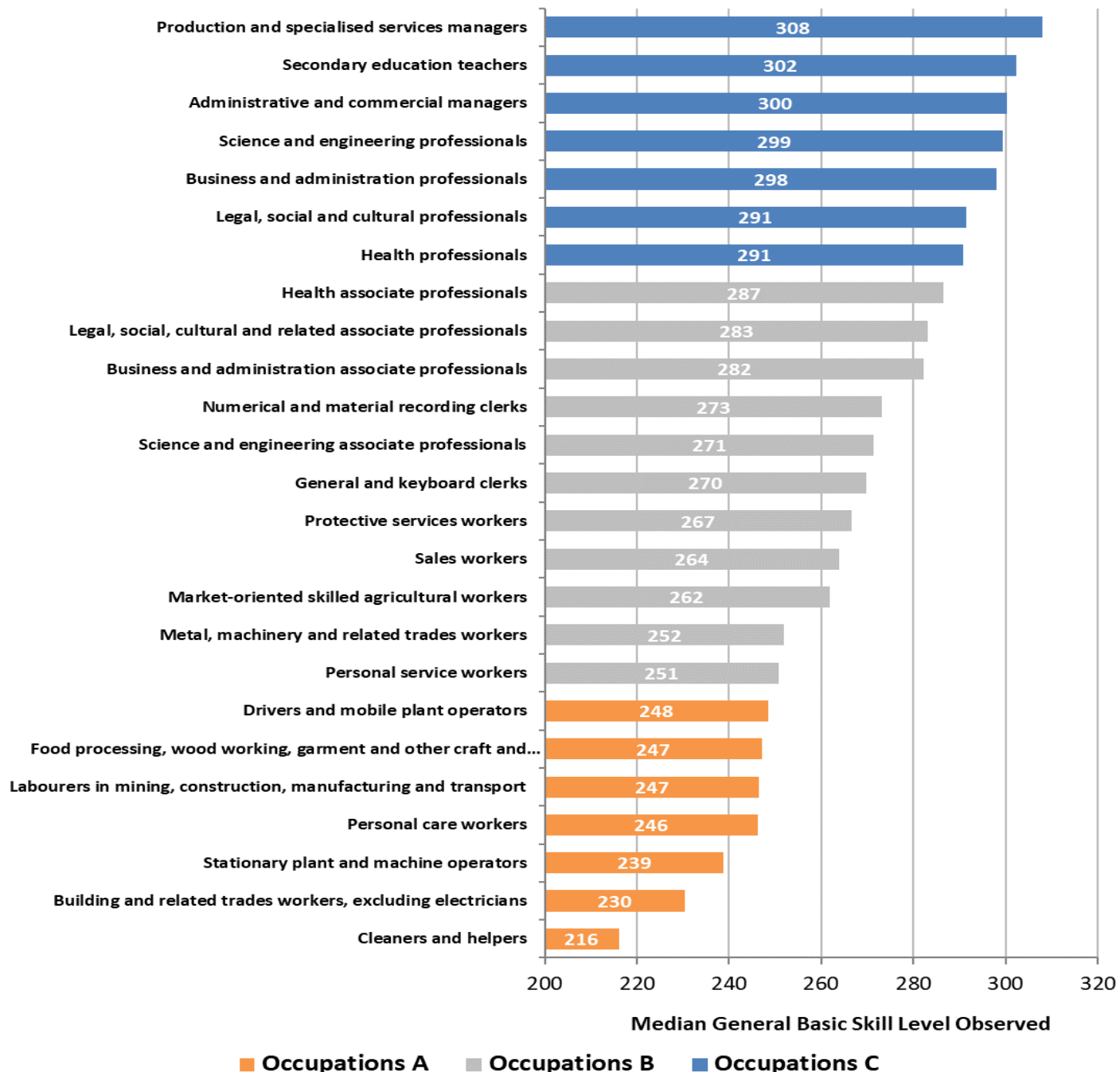

Note: the "cleaners and helpers" occupation (median general skill score of 216) belongs to the quartile of occupations with an apparent skills mismatch that have the lowest median skill scores (category A).

Source: PIAAC 2012, OECD, Calculations by France Stratégie.

44. For each category, we observed the characteristics of individuals whose skill level is above or below the proxies for the occupation and training profile using PIAAC survey data (age, gender, selfreported health status, self-reported job satisfaction, possible need for training, whether respondents 
consider they have the skills to cope with more demanding duties). This enables us to gain a better understanding of the profile of individuals and to analyse their apparent skills mismatch in more detail.

Figure 11. Structure of the classification of skills mismatches by occupation category and positioning in relation to the proxies for the occupation and training profile

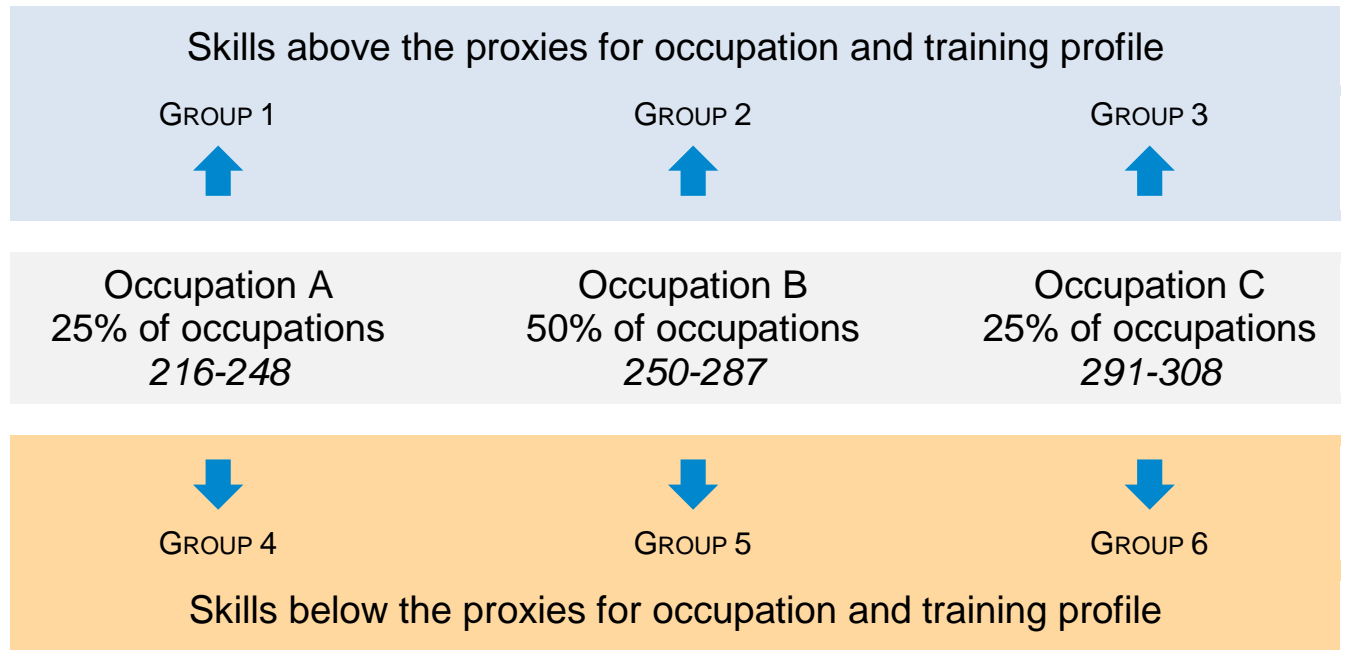

Source: France Stratégie.

45. In the first category of occupations with the lowest median skill scores (see figure. 12), individuals with skill levels above the proxies for their occupation and training profile (Group 1) are relatively young compared to the national average (for the occupations observed) or to occupations in Group A (30\% are under 30 years of age compared to $19 \%$ and $19 \%$ respectively), report that they are generally in good health, do not express a greater need for training than the national average, but are more likely to report being able to perform more demanding duties ( $89 \%$ versus $80 \%$ for all occupations observed in this study).

\section{Figure 12. Characteristics of individuals in Group 1, Group A occupations and at national level}

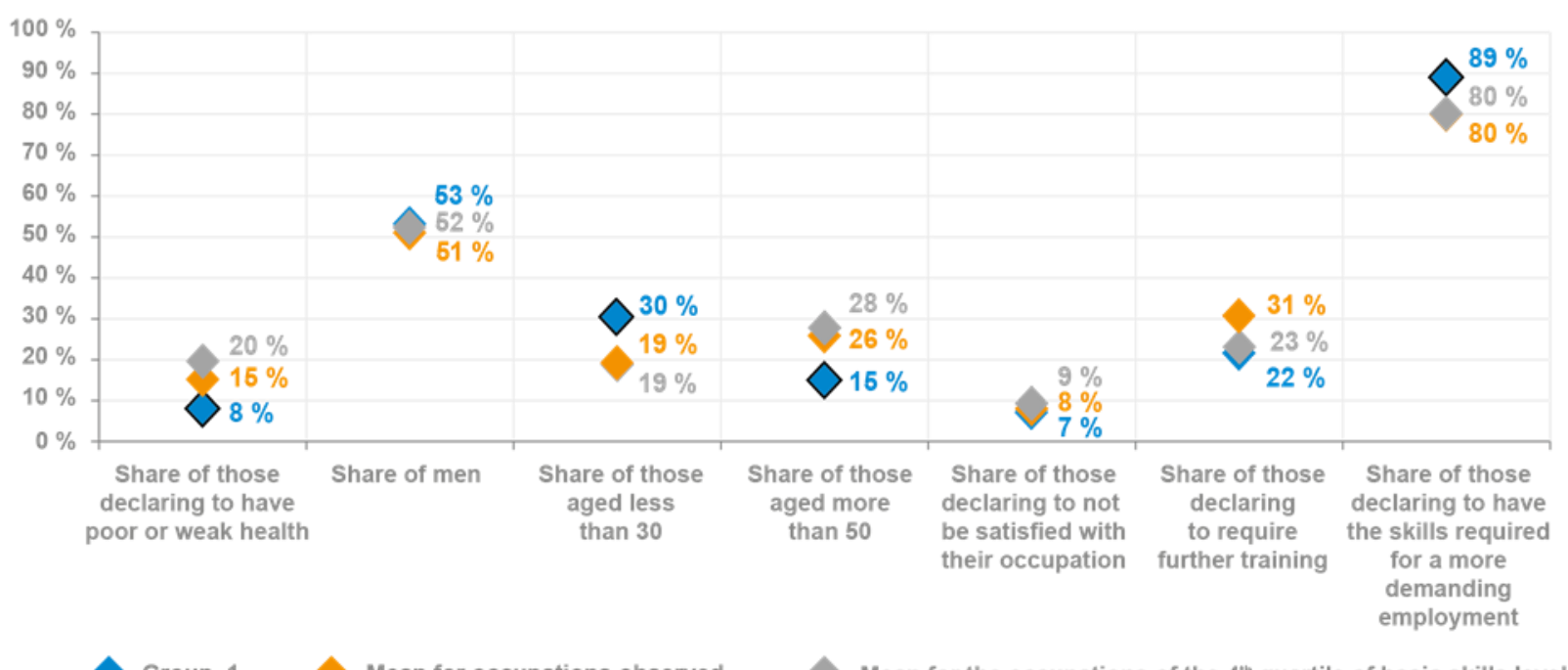

Note: Statistically significantly different scores for each variable between Group. 1 and the means observed for the occupations in the $4^{\text {th }}$ quartile of basic skills set are distinguished with a black border.

Source: PIAAC 2012, OECD, Calculations by France Stratégie. 
46. These observations indicate a skills mismatch in the sense that these individuals declare themselves capable of performing more demanding duties and have a skill score above the proxies for their occupation and training profile. This does not mean that they would not benefit from training, but rather that the analysis tends to show that they are in jobs that are inappropriate to their skill level.

47. For the same category of occupations with the lowest skill scores, but for individuals with skill levels below the proxies for their occupation and training profile (Group 4, see figure. 13), the characteristics are different. Compared to the national average and to the average for these occupations, these individuals report more poor health, are older, do not express a need for training, and a smaller proportion of them say they are able to perform more demanding duties $(68 \%$, compared to $80 \%$ for all occupations observed and occupations in Group A). In this case, the apparent skills mismatch is more indicative of a low individual skill level than of a skills mismatch. The low skill level could be addressed through training and coaching to achieve a higher level of basic skills. We recall here that these occupations have one of the lowest median skill levels in France.

\section{Figure 13. Characteristics of individuals in Group 4, Group A occupations and at national level}

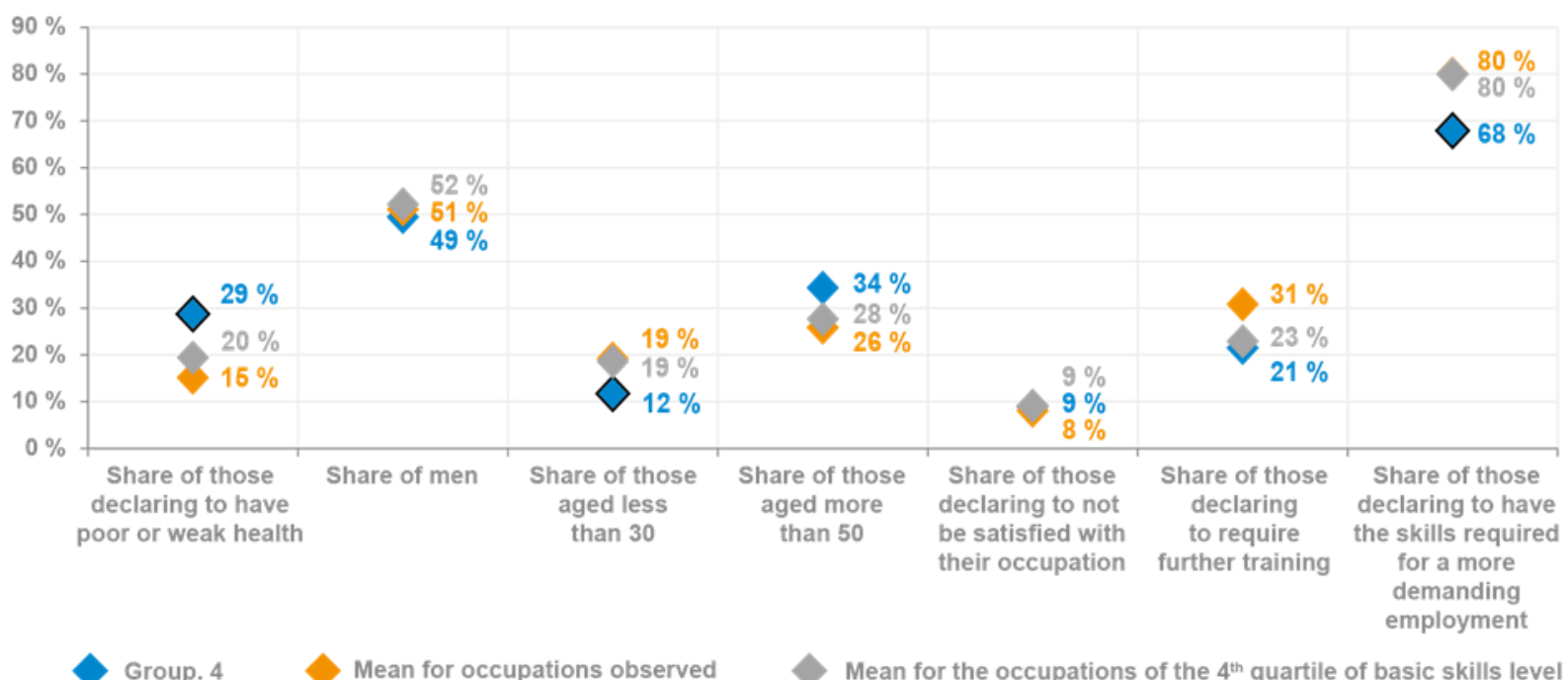

Note: Statistically significantly different scores for each variable between Group. 4 and the means observed for the occupations in the $4^{\text {th }}$ quartile of basic skills set are distinguished with a black border.

Source: PIAAC 2012, OECD, Calculations by France Stratégie.

48. For the occupations with the highest median scores, we looked at the characteristics of individuals whose skill scores are above the proxies for their occupation and profile (Group 3, see figure 14). Compared to the national average and to the first quartile occupations, the individuals whose skill level is above the proxies for their occupation and training profile are more likely to be young men who do not report that they are dissatisfied with their work and who feel, to a lesser extent, that they have sufficient skills to perform more demanding tasks (75\% compared to $80 \%$ for all occupations observed and $80 \%$ for occupations in Group A). In this case, the apparent skills mismatch observed does not necessarily indicate a skills mismatch, but rather attests to superior individual performance. 
Figure 14. Characteristics of individuals in Group 3, Group C occupations and at national level

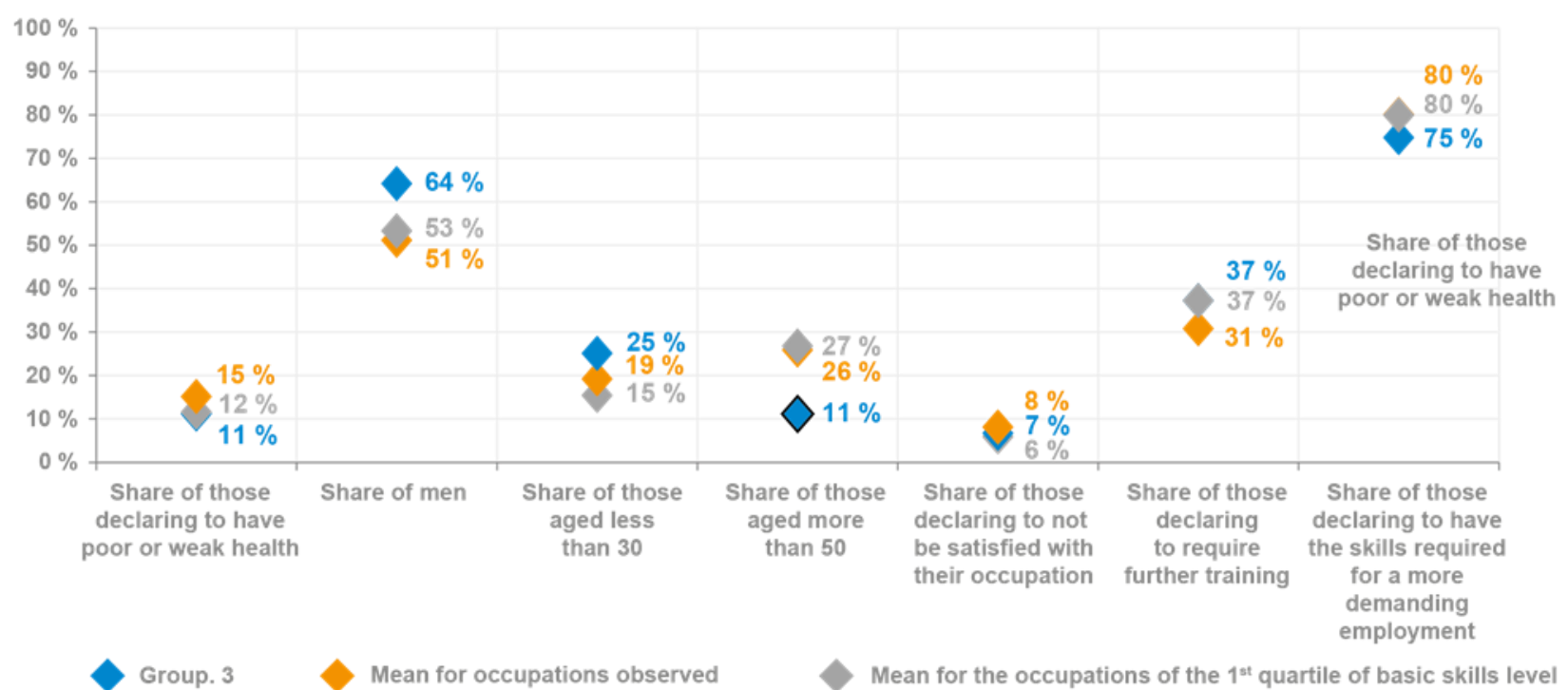

Note: Statistically significantly different scores for each variable between Group. 3 and the means observed for the occupations in the $1^{\text {st }}$ quartile of basic skills set are distinguished with a black border.

Source: PIAAC 2012, OECD, Calculations by France Stratégie.

49. For these same occupations, individuals with lower skill levels than the proxies for occupation and training profile (Group 6, see figure 15) are more likely to be women, over 50 years of age (48\%) and in poor health, report more than average dissatisfaction with their jobs and need training. For this category, the question of whether jobs are appropriate to skill levels could be reviewed.

Figure 15. Characteristics of individuals in Group 6, Group C occupations and at national level

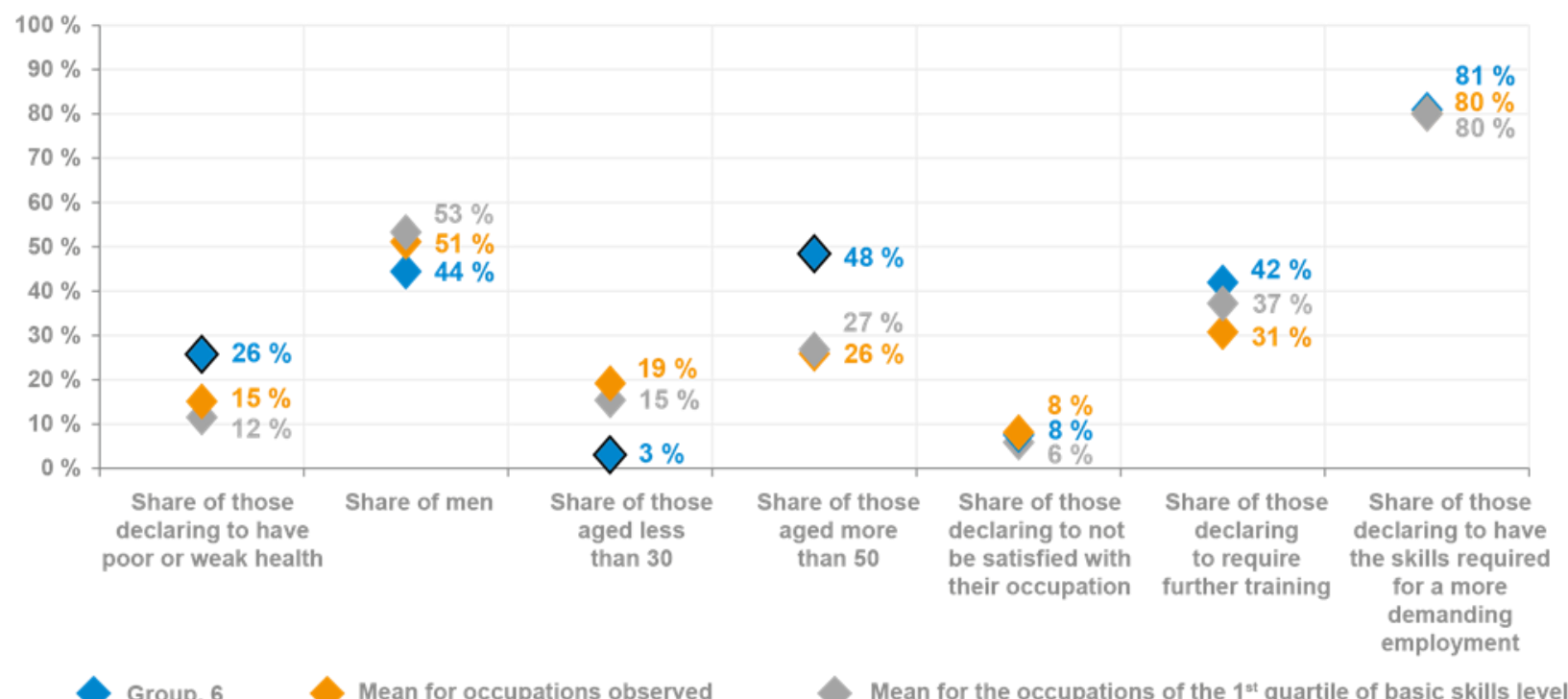

Note: Statistically significantly different scores for each variable between Group. 6 and the means observed for the occupations in the $1^{\text {st }}$ quartile of basic skills set are distinguished with a black border.

Source: PIAAC 2012, OECD, Calculations by France Stratégie. 
50. For the occupations with a median skill score in the middle of the range, individuals with a skill score above the proxy for the occupation and training profile (Group 2, see figure. 16) are generally young, and generally report being in good health compared to the national and occupation group average. They report more of a need for training when their skill level is above the proxy for the occupation and their training profile. Nevertheless, the proportion of individuals reporting that they are satisfied with their jobs and have the skills to perform more demanding duties is around the national and occupation group average. These individuals, who more often than not have higher vocational education qualifications (19\% compared to $17 \%$ for occupation Group A and $12 \%$ at the national level), should be working in an activity more in line with their skill level.

\section{Figure 16. Characteristics of individuals in Group 2, Group B occupations and at national level}

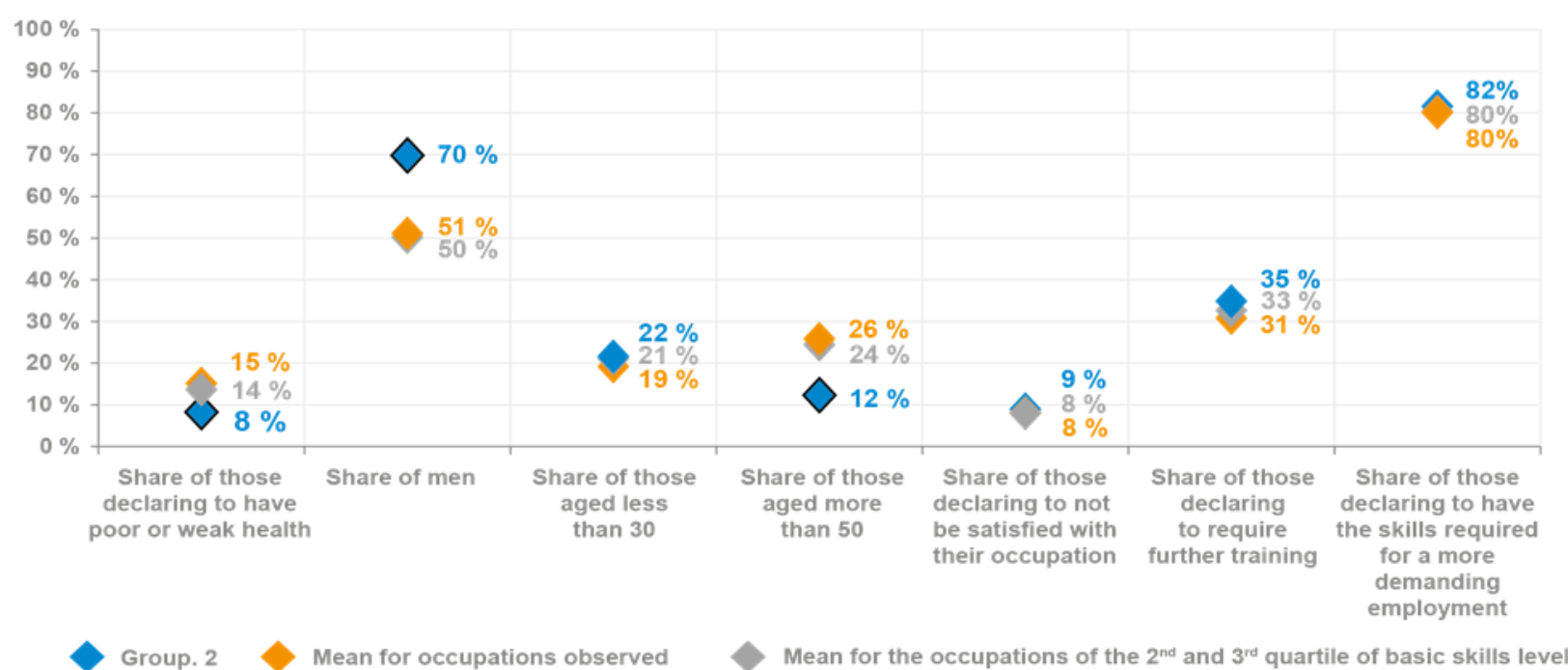

Note: Statistically significantly different scores for each variable between Group. 2 and the means observed for the occupations in the $2^{\text {nd }}$ and $3^{\text {rd }}$ quartile of basic skills set are distinguished with a black border.

Source: PIAAC 2012, OECD, Calculations by France Stratégie.

51. For these same occupations, individuals whose level of basic skills (Group. 5, see figure. 17) is below the proxy for their occupation and training profile are more likely to be over 50 years of age and to report poorer health. They more often report being dissatisfied with their jobs and needing training than the national average. The apparent skills mismatch may more likely mean that these individuals are in jobs that are inappropriate to their skill level. Support for a career change and more training would be desirable. 
Figure 17. Characteristics of individuals in Group 5, Group B occupations and at national level

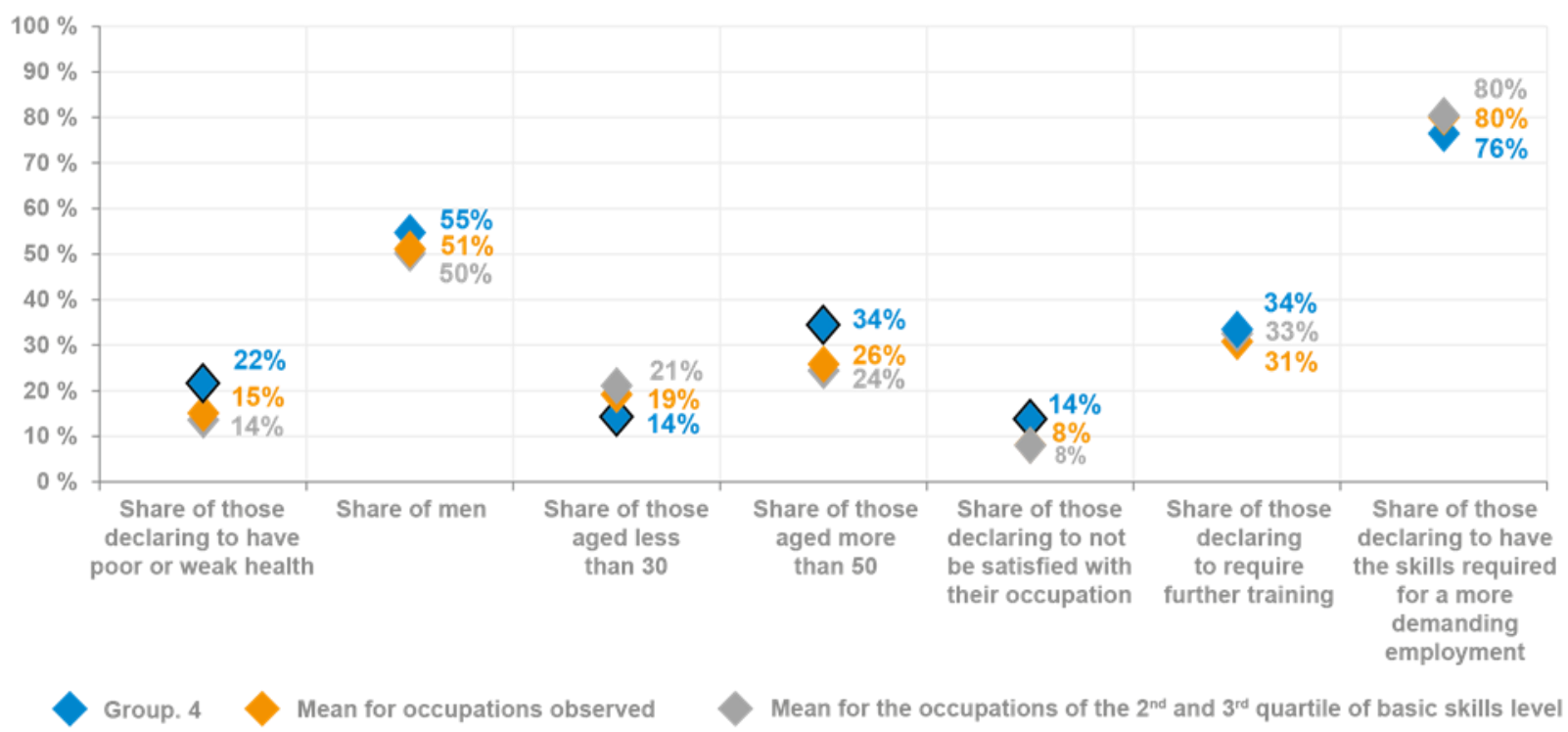

Note: Statistically significantly different scores for each variable between Group. 4 and the means observed for the occupations in the $2^{\text {nd }}$ and $3^{\text {rd }}$ quartile of basic skills set are distinguished with a black border.

Source: PIAAC 2012, OECD, Calculations by France Stratégie.

\subsection{Cognitive and task-based skills}

52. This study proposes the notion that skills-mismatch, being a structural phenomenon, must not be measured or quantified in the same nature that a skills-level is. Whilst the two are intrinsically linked, the conceptualisation of skills mismatch must be conducted through the confrontation of the skills available in the labour market, and the skills required for each occupation and position whilst also understanding the mechanism through which these "supply" and "demand" side resources are matched. However, the calculations presented so far have been done so with the direct evaluation of skills offered by the PIAAC survey which can be characterised as being cognitive in nature. Moving forwards with this new methodology for identifying skills-mismatch, it is nonetheless important to acknowledge the growing importance attributed to task-based skills in modern skills literature.

53. Indeed, a growing body of work acknowledges that whilst cognitive abilities, and specifically the ability to learn, can act as a suitable predicter of occupational success and outcomes (Schmidt and Hunter, 2004), more recent publications indicate that the understanding of job-to-job proximity and the relating of human capital factors to other economic fields must be conducted with an association between cognitive and task-based skills. As an example, Grundke et. al. (2017) provide a factor analysis based framework which relates both cognitive and non-cognitive skills indicators (from the PIAAC survey) in order to further understand the role of human capital in Global Value Chains and productivity. Amongst, the different mechanisms evaluated, this paper was able to find a positive significant correlation between labour productivity and cognitive skills indicators as well as with a task-based indicator named "ICT". This indicator was identified through using variables asking if a participant uses a specific type of software (Word, Excel etc.) as well as other similar types of information. Furthermore, a deeper evaluation of the relations between the indicators developed and global integration was able to find evidence for the important role played by cognitive skills, ICT, management and communication task-based skills as well as the readiness to learn.

54. Task-based skills may also be integrated into the evaluation and study of skills mismatch. Bechichi et. al. (2018) in a similar fashion to the methodology proposed in this study identify a proxy for the level of 
skill required in a range of occupations using the PIAAC survey for both cognitive and task-based skills. Through conducting a comparison between each occupation, a distance in skills was established and therefore was able to distinguish between the general need for cognitive improvement and the acquisition of new task-based abilities in order to allow professional transitions. Through their methodology, they were able to postulate that differences in cognitive abilities and task-based abilities required in each profession could potentially be an explicative factor for the polarisation of the labour market observed in many countries today.

55. Overall, whilst this study did not include task-based skills as a complement to cognitive skills in its analysis, further reflexions to integrate this type of information within our framework would be a considerable asset. A caveat to this, requiring special consideration, is that task-based knowledge is often acquired "on-the-job" and the simple use of degree as a skills-signal may not be adequate for this type of skill and an alternative proxy may be required.

\section{Conclusion}

56. Although based on stylised facts, our analysis enables us to infer whether an apparent skills mismatch relates to under/over-skilling or performance. Based on this classification and by observing the workforce in each category, we estimate that about two-thirds of the individuals with an apparent skills mismatch in relation to their occupation and training profile may be under/over-skilled - or about $12 \%$ of those employed in the occupations observed. This figure is only an approximation and is intended only to give an order of magnitude. Nevertheless, it is important to consider that a difference in skill levels within an occupation does not necessarily constitute a skills mismatch, but may also relate to individual performance. In the case of inadequate individual performance, further training plays an essential role. Indeed, as we have been able to show, age is a significant factor in cases of apparent skills mismatch. The feasibility of a career change decreases with age, which reinforces the role that continuing education should play in these cases. 


\section{References}

French National Productivity Board (2019), "First report - Productivity and competitiveness: where does France stand in the Euro zone?", 10, July.

Allen J. and van der Velden R. (2001), "Educational Mismatches versus Skill Mismatches: Effects on Wages, Job Satisfaction, and On-the-Job Search", Oxford Economic Papers, vol. 53(3), pp. 434-452, 1, July.

Green F. and Mcintosh S. (2007), "Is there a Genuine Under-utilisation of Skills Amongst the Overqualified? ", Applied Economics, 39(04), p 427-439, February.

Hauret L. and Marguerit D. (2020), "L'inadéquation des compétences au Luxembourg : un employé sur deux concerné ", Les rapports du Liser (Luxembourg Institute of Socio-Economic Research), August.

Quintini G. (2014), "Skills at Work: How Skills and their Use Matter in the Labour Market", OECD Social, Employment and Migration Working Papers, No. 158, OECD Publishing, Paris.

Adalet McGowan M. and Andrews D. (2015), "Labour Market Mismatch and Labour Productivity: Evidence from PIAAC Data", OECD Economics Department Working Papers, No. 1209, OECD Publishing, Paris.

Pellizzari M. and Fichen A. (2017), "A new measure of skill mismatch: theory and evidence from PIAAC", IZA Journal of Labor Economics, vol. 6(1), December.

Zinn, S, Landrock, U. and Gnambs T., 2020, "Web-based and mixed-mode cognitive large-scale assessments in higher education: An evaluation of selection bias, measurement bias, and prediction bias.", Behaviour Research Methods, October

Mini C. (2012), "Emploi et chômage des immigrés en 2011", Dares analyses no. 77, October.

France Stratégie (2019), "The impact of immigration on the labour market, public finances and economic growth", report for the National Assembly, July.

Schmidt, F. L. and Hunter, J. (2004), General Mental Ability in the World of Work: Occupational Attainment and Job Performance. Journal of Personality and Social Psychology, 86(1), 162-173.

Grundke, R., et al. (2017), "Skills and global value chains: A characterisation", OECD Science, Technology and Industry Working Papers, No. 2017/05, OECD Publishing, Paris

Bechichi, N., et al. (2018), "Moving between jobs: An analysis of occupation distances and skill needs", OECD Science, Technology and Industry Policy Papers, No. 52, OECD Publishing, Paris 


\section{Annex A. The OECD's PIAAC survey}

1. The aim of the OECD's PIAAC (Programme for the Assessment of Adult Competencies) survey also known as the Survey of Adult Skills - is to gain a better understanding of the competencies that individuals living in OECD countries possess and how they apply them in their occupations. The assessment of skills in an adult population, as designed by PIAAC, focuses on the use of literacy and numeracy in everyday life and work. The main goal is to examine whether respondents have a sufficient level of mastery to cope with the changes and demands of the world of work and daily life. This household survey uses the concepts of "literacy" and "numeracy" to refer to the literacy and numeracy skills used in everyday situations. The PIAAC project is based on computer-based tests. It places the people surveyed in situations using digital environments (website, email, spreadsheet, etc.).

2. The PIAAC survey is a unique source providing an international comparison of adult skills on a harmonised basis. No other comparable exercise exists. The survey was first carried out in 2012 and the next cycle is planned for 2022.

3. For France, the PIAAC survey has a sample of approximately 7,000 respondents. The occupations of the individuals surveyed are classified according to the ISCO (International Standard Classification of Occupations) nomenclature. The focus is on the basic skills observed in the PIAAC survey. The indicators of skills observed are obtained from the scores achieved by individuals on the various tests in the PIAAC survey, which provide an understanding of their level of basic literacy and numeracy skills. The overall skills indicator is a simple average of the numeracy and literacy skill scores. 


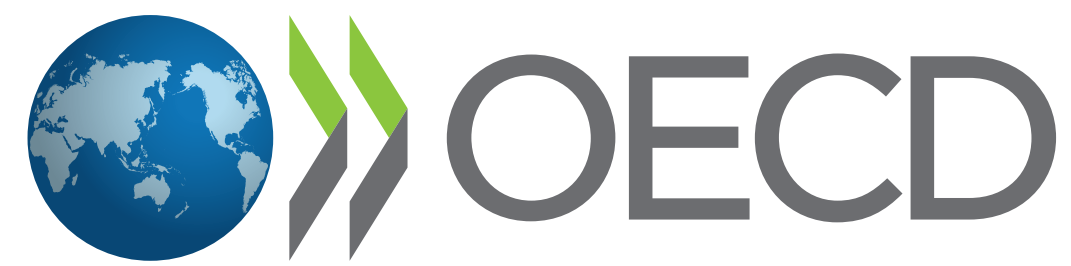

BETTER POLICIES FOR BETTER LIVES 